\title{
Fractal Antennas: An Historical Perspective
}

\author{
Jaume Anguera ${ }^{1,2, *}$, Aurora Andújar ${ }^{1}$, Jeevani Jayasinghe ${ }^{3}$, V. V. S. S. Sameer Chakravarthy ${ }^{4}(\mathbb{0}$, \\ P. S. R. Chowdary ${ }^{4}\left(\mathbb{D}\right.$, Joan L. Pijoan ${ }^{2}\left(\mathbb{D}\right.$, Tanweer Ali ${ }^{5}(\mathbb{D})$ and Carlo Cattani ${ }^{6}(\mathbb{C})$
}

1 Fractus Antennas, 08174 Barcelona, Spain; aurora.andujar@fractusantennas.com

2 Electronics and Telecommunication Department, Universitat Ramon LLull, 08022 Barcelona, Spain; joanlluis.pijoan@salle.url.edu

3 Department of Electronics, Wayamba University of Sri Lanka, 60170 Kuliyapitiya, Sri Lanka; jeevani@wyb.ac.lk

4 Department of Electronics and Communication Engineering, Raghu Institute of Technology, Visakhapatnam 531162, India; sameervedula@ieee.org

5 Department of Electronics \& Communication Engineering, Manipal Institute of Technology, Manipal Academy of Higher Education, Manipal 576104, India; tanweer.ece@gmail.com

6 Engineering School, DEIM, Tuscia University, 01100 Viterbo, Italy; cattani@unitus.it

* Correspondence: jaume.anguera@salle.url.edu or Jaume.anguera@fractusantennas.com; Tel.: +34-93-290-24-00

Received: 13 November 2019; Accepted: 8 January 2020; Published: 19 January 2020

\begin{abstract}
Fractal geometry has been proven to be useful in several disciplines. In the field of antenna engineering, fractal geometry is useful to design small and multiband antenna and arrays, and high-directive elements. A historic overview of the most significant fractal mathematic pioneers is presented, at the same time showing how the fractal patterns inspired engineers to design antennas.
\end{abstract}

Keywords: fractals; antennas; fractal antennas; self-similar; space-filling; mass fractals; Mandelbrot; Sierpiński; Koch; Hilbert; Cantor; Minkowski; Peano

\section{Introduction}

The term fractal was first coined by B. Mandelbrot, considered the father of the fractal geometry. The word comes from the Latin word "fractus", which means irregular or broken [1]. This term was used to describe a new set of more complex objects than squares, circles, or triangles which were well defined using the Euclidean geometry. However, other quotidian objects, such as clouds, blood vessels, and irregular shapes such as the coast couldn't be described by Euclidean geometry.

Besides B. Mandelbrot, other great mathematicians contributed as well to the field of fractal geometry: W. Sierpiński, N. F. H. von Koch, D. Hilbert, G. F. L. P. Cantor, H. Minkowski, and G. Peano. Their fractals inspired the antenna engineering community to research if those geometries could be used as antennas [2-7]. In this regard, the present papers present an historic background of their lives and some antenna designs inspired in the fractals they propose.

The paper is structured as follows: In Section 2, a brief introduction to fractal geometry is presented. In Section 3, a review of some antenna designs inspired by fractal patterns is reviewed. In Section 4, the impact of fractal antenna in the literature is reported. Finally, in Section 5, the conclusions are drawn.

\section{About the Fractal Geometry}

What is a fractal? Following B. Mandelbrot's definition "a set for which the Hausdorff-Besicovitch dimension strictly exceeds the topological dimension" [1]. The topological dimension is a dimension which we use to experience. For example, the topological dimension of a point, line, surface, and volume is $0,1,2$, and 3 , respectively. From an engineering perspective, the box-counting dimension 
can used instead of the Hausdorff-Besicovitch dimension, being the box-counting easy to compute. This dimensional aspect of fractals is however beyond the scope of the paper, and the reader can refer to $[1,8,9]$ for further study on this subject.

Some fractals feature copies of the whole structure at small scales. This property is called self-similarity, and it is useful to design multiband antennas. The Sierpiński triangle is one of the most known self-similar fractals. Some other fractals fill the space, as is the case of space-filling curves, that make them attractive to design small-antennas. The Hilbert curve is one example of a space-filling curve which has been used to design small antennas.

Generation of fractals: The process of generation of fractals can be explained by the following procedures.

\subsection{Recursive Relation Based}

In the spatial domain, a recurrence relation is defined to produce these types of fractals in a complex plane. Some examples of such fractals are Mandelbrot set, Julia set, Lyapunov fractal, etc. This is also known as escape-time method of generating fractals. This technique uses recursive mathematical equations.

Let us define a transformation function in a complex plane.

$$
H=f(X) \text {, where } f(X)=z^{2}+c
$$

Here, $\mathrm{c}$ is any given complex number. This generates a set of points which can diverge or converge over an orbit. This entirely depends on the constant used in the transformation. While it is diverging, the process of generating next set should progress until the convergence is achieved. The convergence typically allows the points to move inward. Now the fractal is said to be completely formed. Examples of antennas following this process are presented in [10-12].

\subsection{Iterated Function System (IFS)}

These geometrical based rules are used to replace specific portion or region repeatedly to produce fractal shapes, also known as Multiple Reduction Copy Machine (MRCM). Some examples of such fractals are Sierpiński carpet, Sierpiński triangle, Koch curve, Peano curve, etc. This technique uses recursive transformations and relations.

The IFS initially refer to a set of transfer functions which acts as a basis of iteration. As the iteration progresses, the corresponding condensation set is filled with solutions, which is a fractal geometry. After successive iterations with the application of IFS, the respective outcome is said to be self-similar. Many examples of fractal-shaped antennas are created following this process [2-4,13-18].

\subsection{L-Systems}

Growing processes can be modelled by an alphabet-based method proposed by A. Lindenmayer in 1968 [9]. Such method is known as L-system, and is useful to create some fractals, such as those based on Hilbert and Peano curves.

\subsection{Random}

The trajectories of non-deterministic functions are used to produce the so-called random fractals. These functions are guided by heavy tails and random nature. Levy flights, Brownian motion, and Brownian tree are some examples of random fractals. Random arrays were first investigated in [19], and random fractals generated by electrochemical deposition have been analyzed to design multiband antennas [20-24]. 


\section{Fractals in Antenna Engineering}

This section reviews some of the most relevant mathematicians working in the fractal area and how some of the fractal shapes derived from their development have inspired antenna engineers to use the fractal geometry in the antenna field to research what benefit can be obtained. In particular, antennas designs inspired in the following mathematicians are reviewed: Mandelbrot, Sierpiński, Koch, Hilbert, Cantor, Minkowski, and Peano. After the extensive work in the field of fractal antenna, the advantages to antenna design are small, multiband, and high-directive antennas, antenna arrays, and frequency selective surfaces.

\subsection{Mandelbrot}

Benoit Mandelbrot (Warsaw 1924-Cambridge 2010) was a Polish Mathematician who moved to France in 1936, where he spent the first part of his life by obtaining French citizenship (Figure 1). His uncle Szolem Mandelbrot was a professor of Mathematics at the Collège de France, so that at the early years of his life, he was easily introduced and with passion to Mathematics by him. From 1945 to 1947, he studied at the École Polytechnique in Paris under the guidance of Gaston Julia and Paul Lévy. From 1947 to 1949, he got a master's in aeronautics at the California Institute of Technology in Pasadena. In 1952, he obtained the PhD in Mathematical Science at the University of Paris while he was working at the French National Center for Scientific Research (CNRS) from 1949 to 1958. Since then, he moved to New York, became an American citizen, and was appointed at the IBM Thomas J. Watson Research Center in Yorktown Heights till retirement in 1987. Thanks to the high-speed computers of these laboratories, he could easily visualize complex geometric objects named after him (Mandelbrot sets). Such enigmatic and astonishing figures, that he proposed in 1975 to call fractals (from Latin "fractus"), attracted the attention of a fast-increasing number of scholars worldwide, thus strongly propelling two of the most fascinating fields of research like fractals and computer graphics. Nowadays, his theory of roughness (everywhere) is accepted in almost every field, from finance to physics to medicine. Contrary to the past, when roughness of non-differentiable geometrical objects was considered a singularity (to be avoided), with Mandelbrot the analysis of non-differentiable objects became an attractive flourishing new research topic. His main contribution, given in particular by the simple recursive equation to define a geometrical object of infinite complexity, like the Mandelbrot set, is worldwide recognized as a milestone in the whole history of Mathematics.

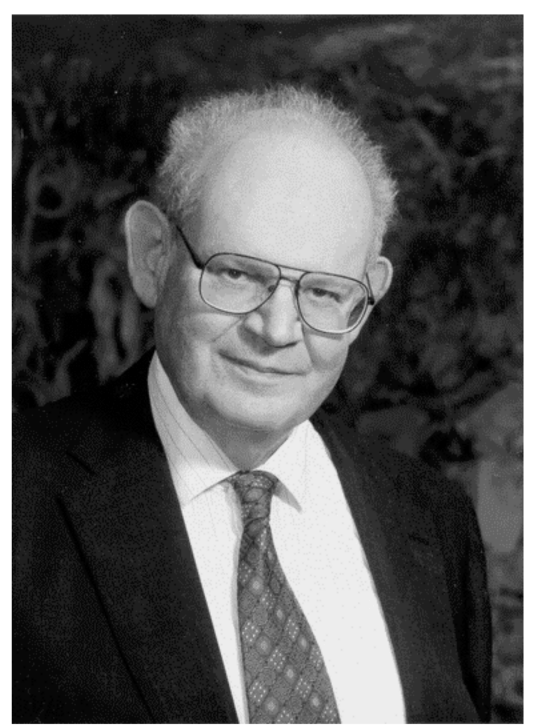

Figure 1. Benoit Mandelbrot (1924-2010), polish mathematician, considered as the father of fractal geometry. 
Using a modification of Mandelbrot equation presented in Section 2 [12], a new set is obtained (Figure 2). This new set has the particularity that it presents a rectangular profile. The idea behind this is to explore higher-order modes supported by the microstrip cavity. In particular, it is interesting to know if those higher-order modes present radiation patterns in the broadside direction (normal to the patch surface) with a high-directivity. Indeed, it has been proven that microstrip antennas having irregular contours such as those provided by fractal geometries, support higher-order modes presenting a broadside radiation pattern, and with a directivity larger than that obtained for the fundamental mode [25-33]. The idea of making the profile rectangular relies in the fact of obtaining a narrow beam in one place and keeping a wide beam in the perpendicular plane. This feature is attractive for antennas in small-cells, such as those providing coverage in hot-spots, because it avoids the use of an array of antennas and the mechanical complexity associated with the feeding network.

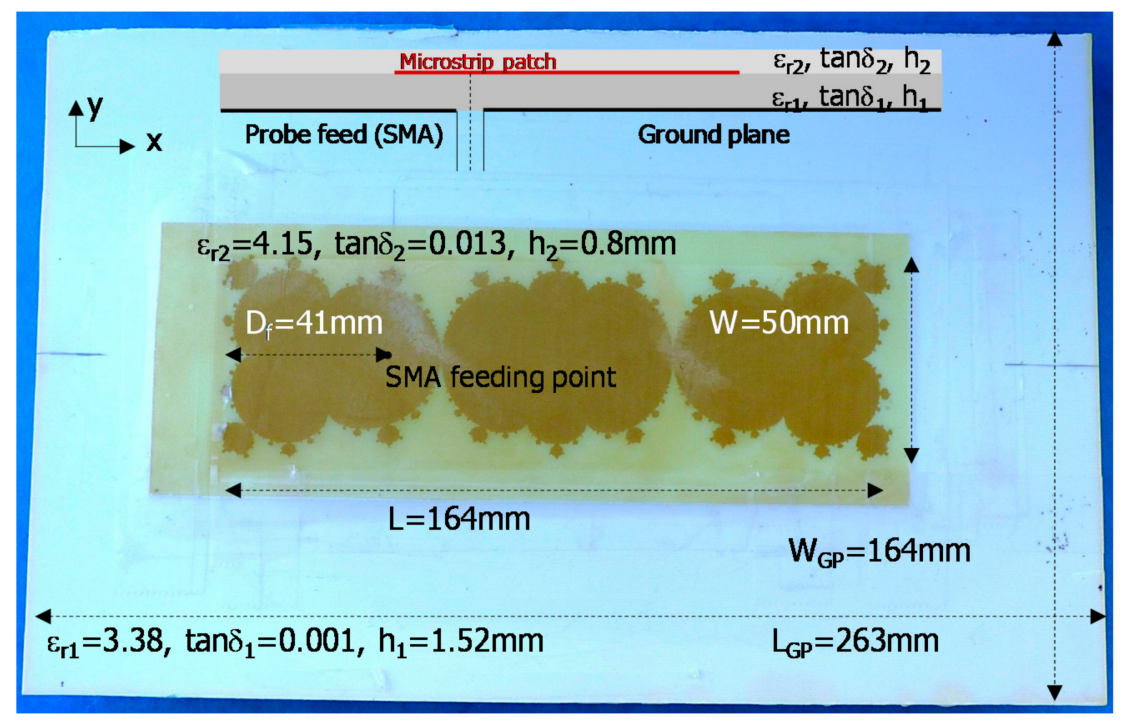

Figure 2. A Mandelbrot based microstrip patch antenna generated using $z_{n+1}=z_{n}{ }^{4}+z_{0}{ }^{2}-1$ [12].

The antenna has been previously simulated using a Method of Moments (MoM) commercial code (Figure 3). Since the modes supported by the microstrip cavity may be excited or not depending on the feeding probe (as the one used in Figure 2), a different approach has been used to find a high-directive mode, which consists on illuminating the patch by a plane wave from the broadside direction. Calculating the backscattering, it is possible to determine if a high-directive mode is supported. For this particular case, a mode is found at $2.75 \mathrm{GHz}$ where the current distribution indicates there is mainly in-phase along the patch area [12].

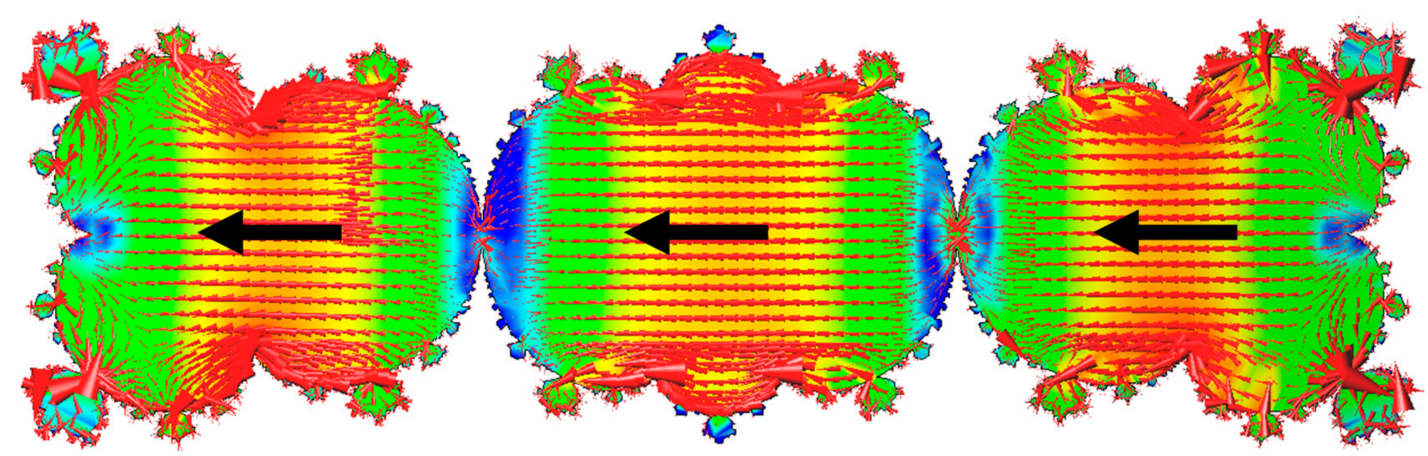

Figure 3. Simulated current distribution at $\mathrm{f}=2.75 \mathrm{GHz}$ using a Method of Moments code. The black arrows (intentionally added) indicate the main flow of the current on the antenna surface. 
The radiation patterns are measured inside an anechoic chamber at the frequency of $2.57 \mathrm{GHz}$ (Figure 4). It is shown how a narrow beam is obtained in the $\varphi=0^{\circ}$ plane due to the electrically large size of the Mandelbrot shape along the x-axis. As a result, the directivity for the antenna at $2.57 \mathrm{GHz}$ is $\mathrm{D}=11.5 \mathrm{~dB}$. This feature is attractive, since several microstrip patches operating in the fundamental mode would be needed to provide the same directivity. In this case, with a single element and one single feeding prove, a high directivity is obtained without the need of including an array. Other Mandelbrot-shapes can be further investigated to find high-directivity modes [12].
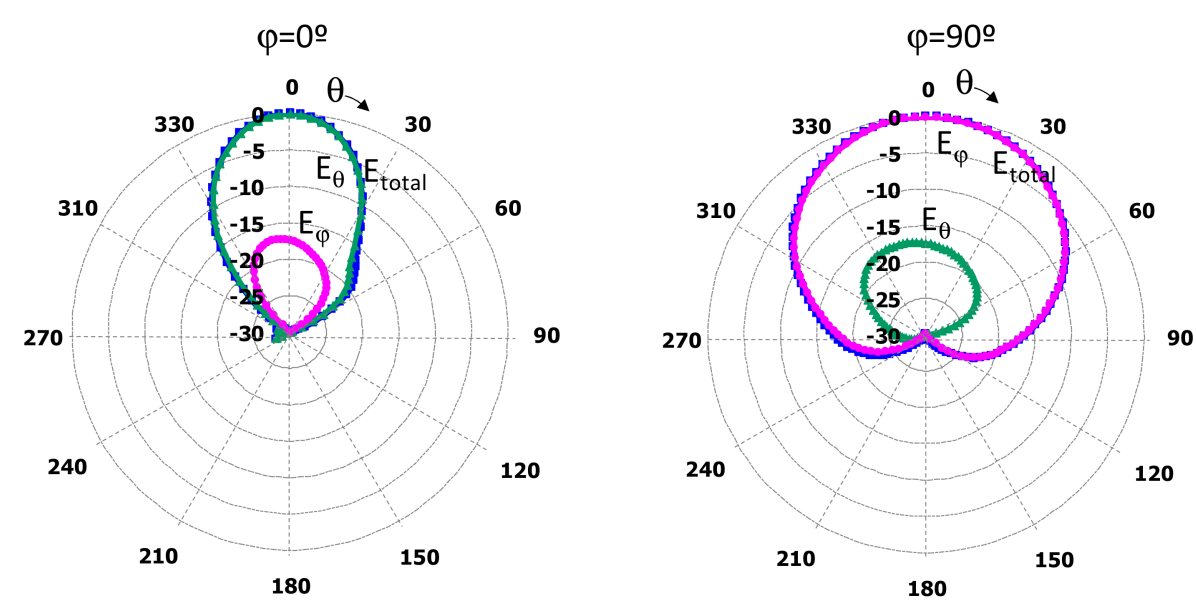

Figure 4. Measured radiation patterns at $\mathrm{f}=2.57 \mathrm{GHz}$ showing the narrow beam at $\varphi=0^{\circ}$.

\subsection{Sierpiński}

Wacław Franciszek Sierpiński (Figure 5), together with Stefan Banach and Kazimierz Kuratowski, is one of the most famous modern Polish Mathematicians (Warsaw 1882-Warsaw 1969). Former student of G. Feodosevic Voronoi, he gave fundamental contributions to functional analysis, number theory, set theory, topology. He has been teaching at the University of Lvov (1908-1914) and Warsaw (1919-1960). Since 1921, he has been a member of the Polish Academy of Science. During the war, in 1914 he was deported to Russia, but thanks to the Russian Mathematicians Egorov and Luzin he was released from detention and could jointly work with Luzin on the foundations of the projective set and theory of real functions. His intensive work, published in more than 700 papers and several books, has deeply influenced the modern developments in Mathematics. Sierpiński's ideas and his fundamental theorems can be found in several modern topics of research. His main contributions to fractals are the Sierpiński curve, which is a square filling curve discovered in 1912, and the Sierpiński Triangle in 1915. Both are very simple in their construction, but still fascinating and amazing examples of fractals. 


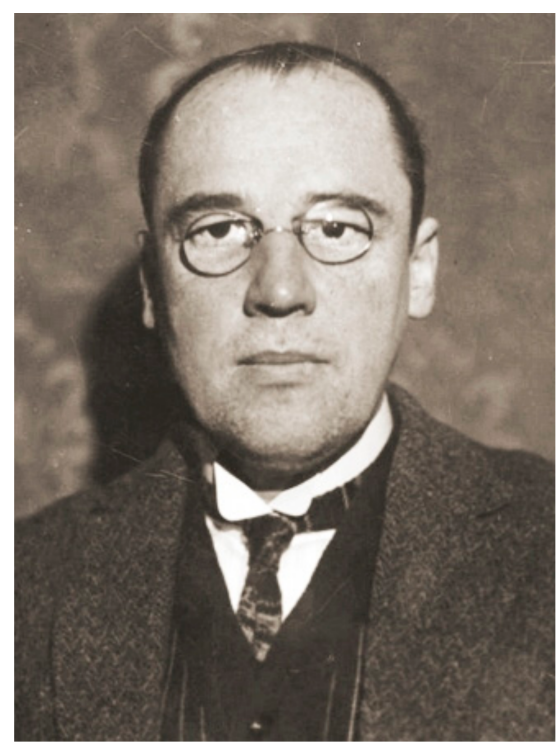

Figure 5. Waclaw Sierpiński (1882-1969), polish mathematician. Well-known fractals such as the Sierpiński triangle or carpet are named after his contributions.

The Sierpiński triangle is one of the most used geometries in the antenna field as well as other variations [34-57]. Due to its self-similarity [13-17], it has been useful to design multiband antennas and frequency selective surfaces.

The Sierpiński triangle is generated through a transformation over the equilateral triangular sub-set $A$ as follows:

$$
V[A]=v_{1}[A] \cup v_{2}[A] \cup v_{3}[A]=\bigcup_{n=1}^{3} v_{n}(A)
$$

for the 1st stage of the Sierpiński gasket (Figure 6) and:

Where $A$ is the triangular subset, $V[A]$ is a Hutchinson operator, which is a transformation over the subset $A$, and $v_{\mathrm{i}}$ is the affine linear transformations [9]. This affine transformation is defined as:

$$
\left(\begin{array}{l}
x \prime \\
y^{\prime}
\end{array}\right)=\left(\begin{array}{cc}
r \cos \phi & -s \sin \psi \\
r \sin \phi & s \cos \psi
\end{array}\right)\left(\begin{array}{l}
x \\
y
\end{array}\right)+\left(\begin{array}{l}
x_{0} \\
y_{0}
\end{array}\right)
$$

where $r$ and $s$ are magnification $(>1)$ or reduction factors $(<1), \phi$ and $\psi$ are the rotation angles, and $x_{0}$ and $y_{0}$ are translations.

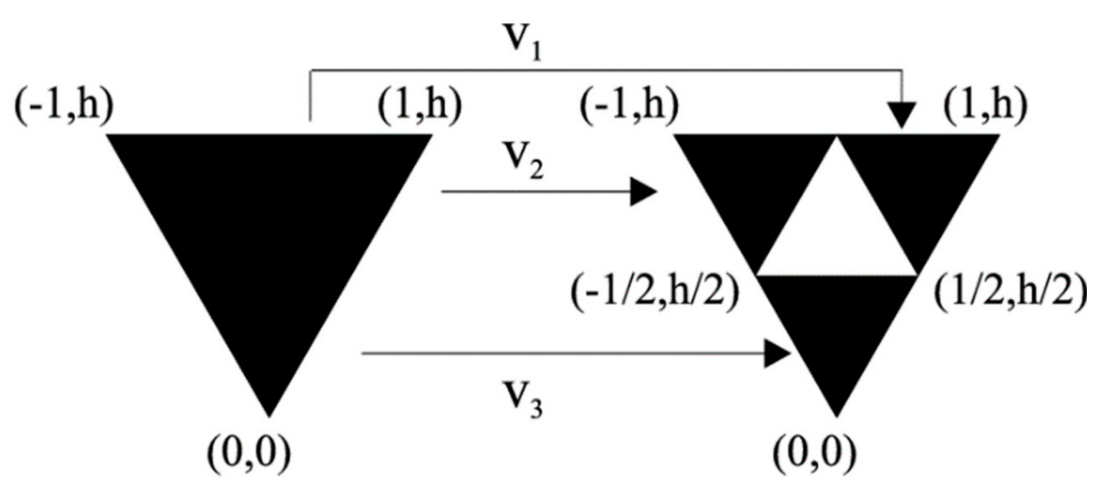

Figure 6. Iteration function process to generate the first stage of the classic Sierpiński gasket. 
For the 1st stage of the Sierpiński gasket (Figure 7), the affine linear transformation is defined by:

$$
\begin{aligned}
& v_{1}(x, y)=\left(\begin{array}{ll}
\frac{1}{2} & 0 \\
0 & \frac{1}{2}
\end{array}\right)\left(\begin{array}{l}
x \\
y
\end{array}\right)+\left(\begin{array}{c}
\frac{1}{2} \\
\frac{\sqrt{3}}{2}
\end{array}\right) \\
& v_{2}(x, y)=\left(\begin{array}{ll}
\frac{1}{2} & 0 \\
0 & \frac{1}{2}
\end{array}\right)\left(\begin{array}{l}
x \\
y
\end{array}\right)+\left(\begin{array}{c}
\frac{-1}{2} \\
\frac{\sqrt{3}}{2}
\end{array}\right) \\
& v_{3}(x, y)=\left(\begin{array}{ll}
\frac{1}{2} & 0 \\
0 & \frac{1}{2}
\end{array}\right)\left(\begin{array}{l}
x \\
y
\end{array}\right)+\left(\begin{array}{l}
0 \\
0
\end{array}\right)
\end{aligned}
$$

As $r=s$ and $\phi=\psi$, the affine linear transformation is a similarity transformation.

One can obtain the ideal Sierpiński fractal iterating infinitely the subset A in the following way:

$$
A_{n}=V\left[A_{n-1}\right]
$$

Then $A_{\infty}$ is the Sierpiński fractal. This iterative process is called the iterated function system (IFS), and $A_{\infty}$ is called the attractor of the IFS. When the contractions $\mathrm{r}$ and $\mathrm{s}$ are different, the final set is no longer self-similar but self-affine, a property which has been useful to allocate the frequency bands $[14,16,38,39]$.

It is precisely this fractal property, the self-similarity, that allows the design of fractal antennas that have the same or very similar radiation patterns at different operating frequencies. A linear antenna, although it can present a good matching in different frequency regions, the radiation pattern changes. Therefore, one possibility to design multi-frequency antennas is to add as many antennas as operation bands. For example, for a system operating at $1 \mathrm{GHz}, 2 \mathrm{GHz}$, and $4 \mathrm{GHz}$, three half-wavelength dipoles could be designed. The drawback of this alternative is that as many antennas as frequency regions, and as many excitation points as antennas are needed, and finally the interaction between antennas that can impair the behavior of the isolated dipole. If, on the other hand, the problem is approached with a self-similar antenna such as the one inspired by the Sierpiński triangle, it is possible to obtain that different regions of the structure operate at a frequency band (Figure 7). In the case of Figure 7, a monopole antenna inspired by the Sierpiński fractal is shown.

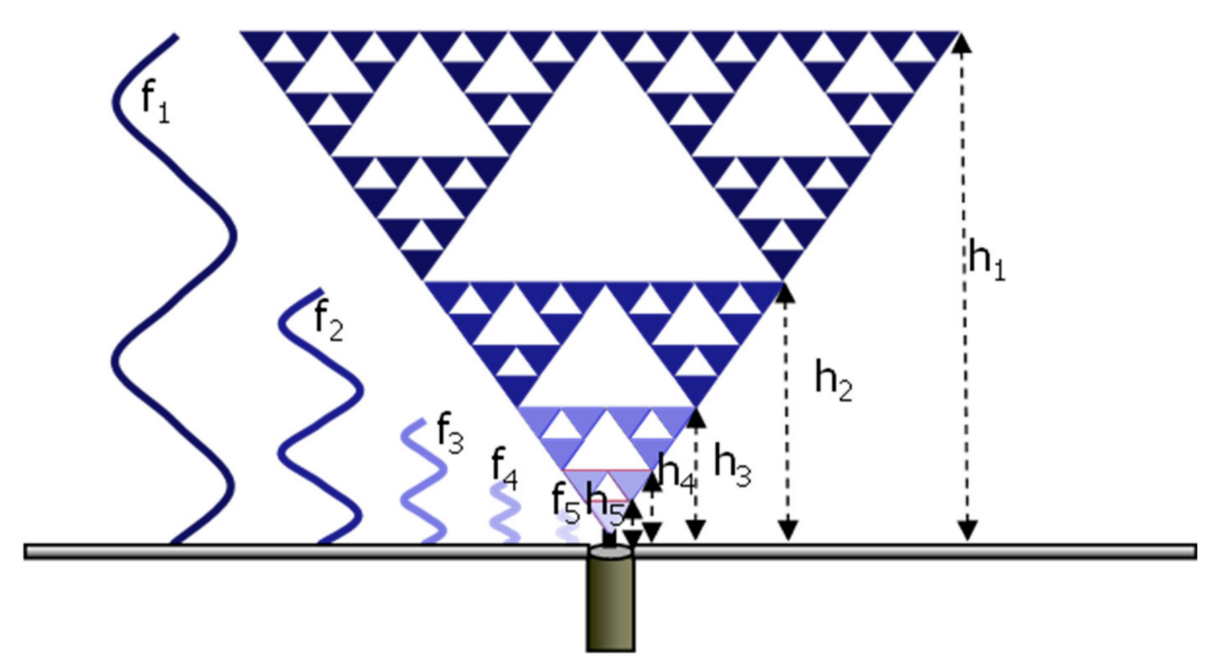

Figure 7. A monopole antenna inspired in the Sierpiński triangle [13].

Properly designed, it can be achieved that for a frequency band centered on $\mathrm{f}_{1}$, the entire structure is responsible for the radiation. Therefore, if the height of this monopole is designed to have a length of $\lambda / 4$, the radiation pattern is obtained with a zero in the zenith direction and with maximum radiation on the horizon (in case of conductors of finite conductivity and finite size, the maximum rises above the horizon. If for a second frequency band with central frequency in $f_{2}\left(f_{2}=2 \cdot f_{1}\right)$ it is achieved that 
the height triangle $h_{2}\left(h_{2}=h_{1} / 2\right)$ practically contributes to the radiation, a type radiation pattern will be again as a $\lambda / 4$ monopole. Additionally, if it is repeated for the next iterations, the same conclusion is reached. In this way, quite similar radiation patterns can be achieved in various frequency regions in addition to a good adaptation for each of the regions (Figures 8 and 9).

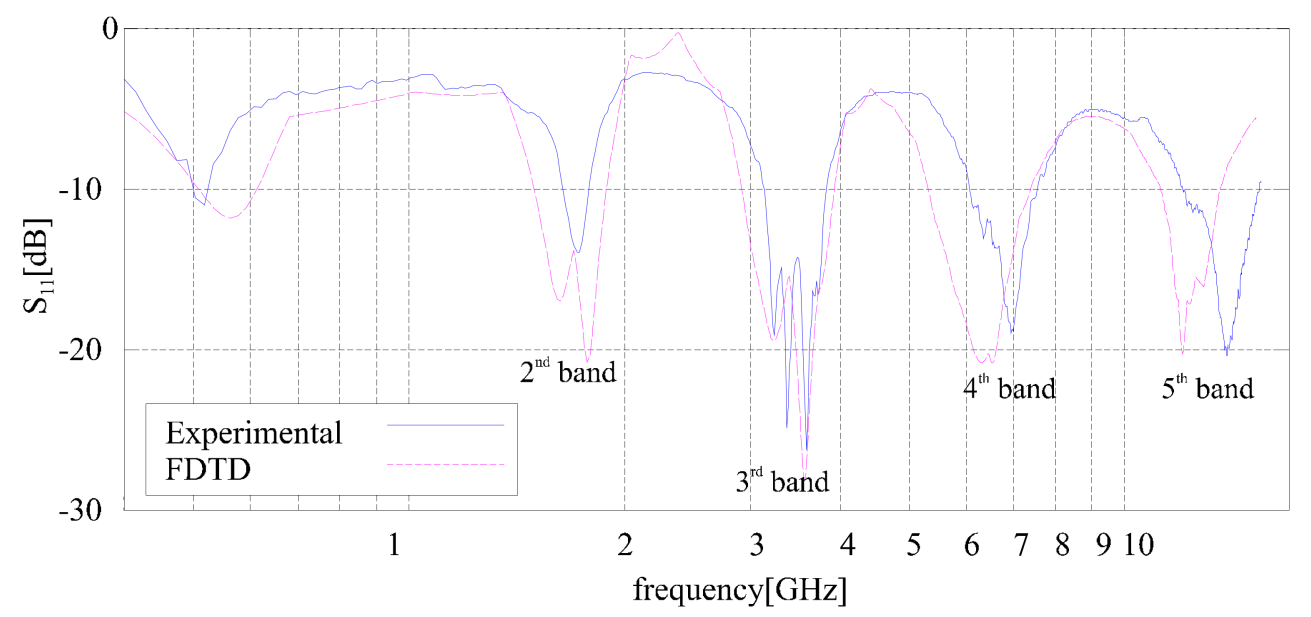

Figure 8. Simulated and measured reflection coefficient of the Sierpiński monopole of Figure 7 [13].

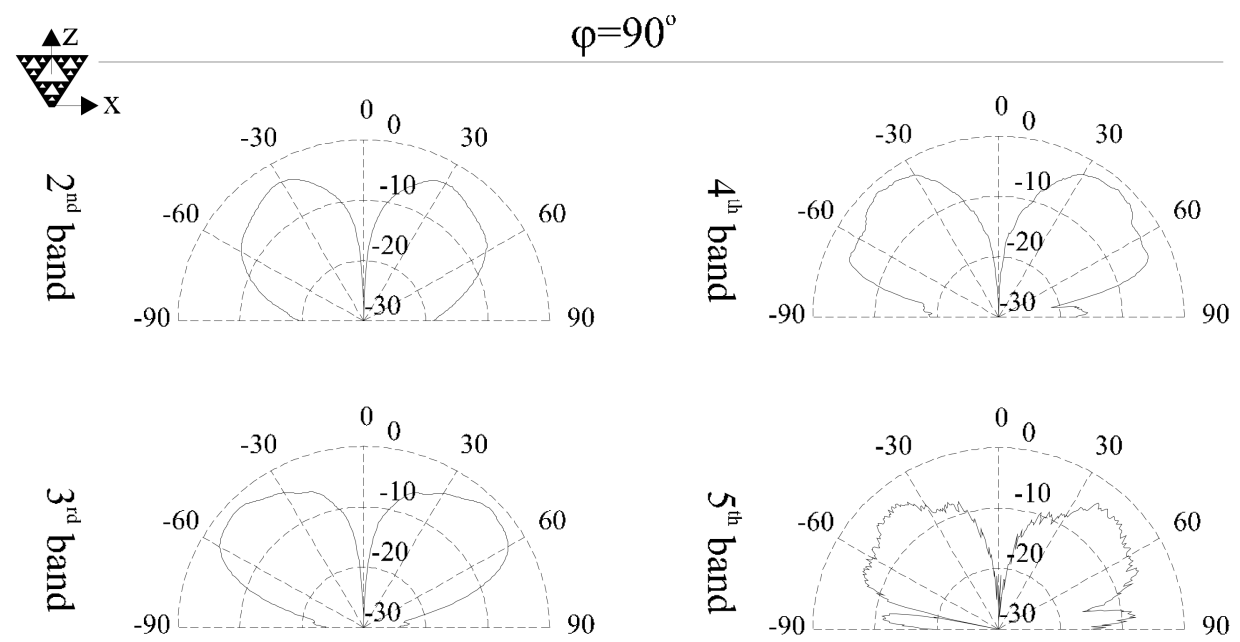

Figure 9. Measured radiation cuts at four frequency bands of the Sierpiński antenna of Figure 7.

Besides the Sierpiński antenna as a multiband behavior, a different feature is also shown. Indeed, the Mandelbrot based antennas presented previously have been proven attractive to design antennas supporting higher-order modes with high-directivity. In this sense, not only microstrip patch antennas having an irregular boundary as the one based on the Mandelbrot geometry support high-directive modes, but also microstrip patch antennas featuring a mass-fractal nature such as the Sierpiński antenna using a bowtie configuration (Figure 10). 


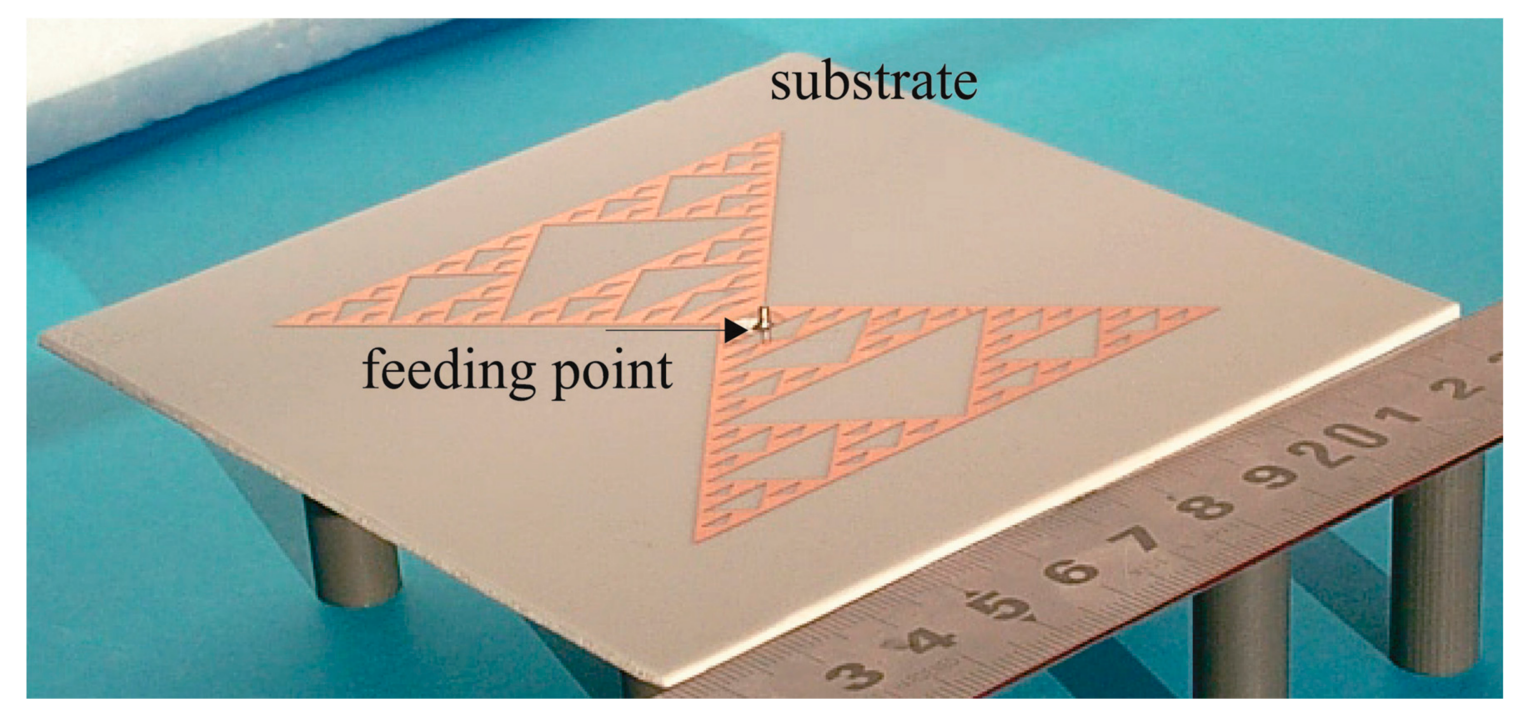

Figure 10. A Sierpiński based microstrip patch antenna fed with a coaxial probe. The size of the ground plane is the same size of the substrate.

The antenna is analyzed using a MoM commercial code where, in this case, different position of the feeding probe has been tested in order to find a high-directivity mode [16]. Once a solution is found in the simulation domain, the antenna is built and tested. Radiation patterns are measured at the fundamental mode and at the higher-order mode (Figure 11). It is shown how both the fundamental and the higher-order mode are broadside with the particularity than the higher-order mode presents a larger directivity than the fundamental mode. This feature is not present in a classic square patch where a higher-order mode with broadside directivity exist $\left(\mathrm{TM}_{30}\right)$, but with large secondary lobes. Therefore, not only fractal inspired boundaries but also mass-fractals are useful to obtain microstrip patch antennas with higher-order modes featuring a larger directivity than the fundamental mode and at the same time keeping a broadside radiation. 

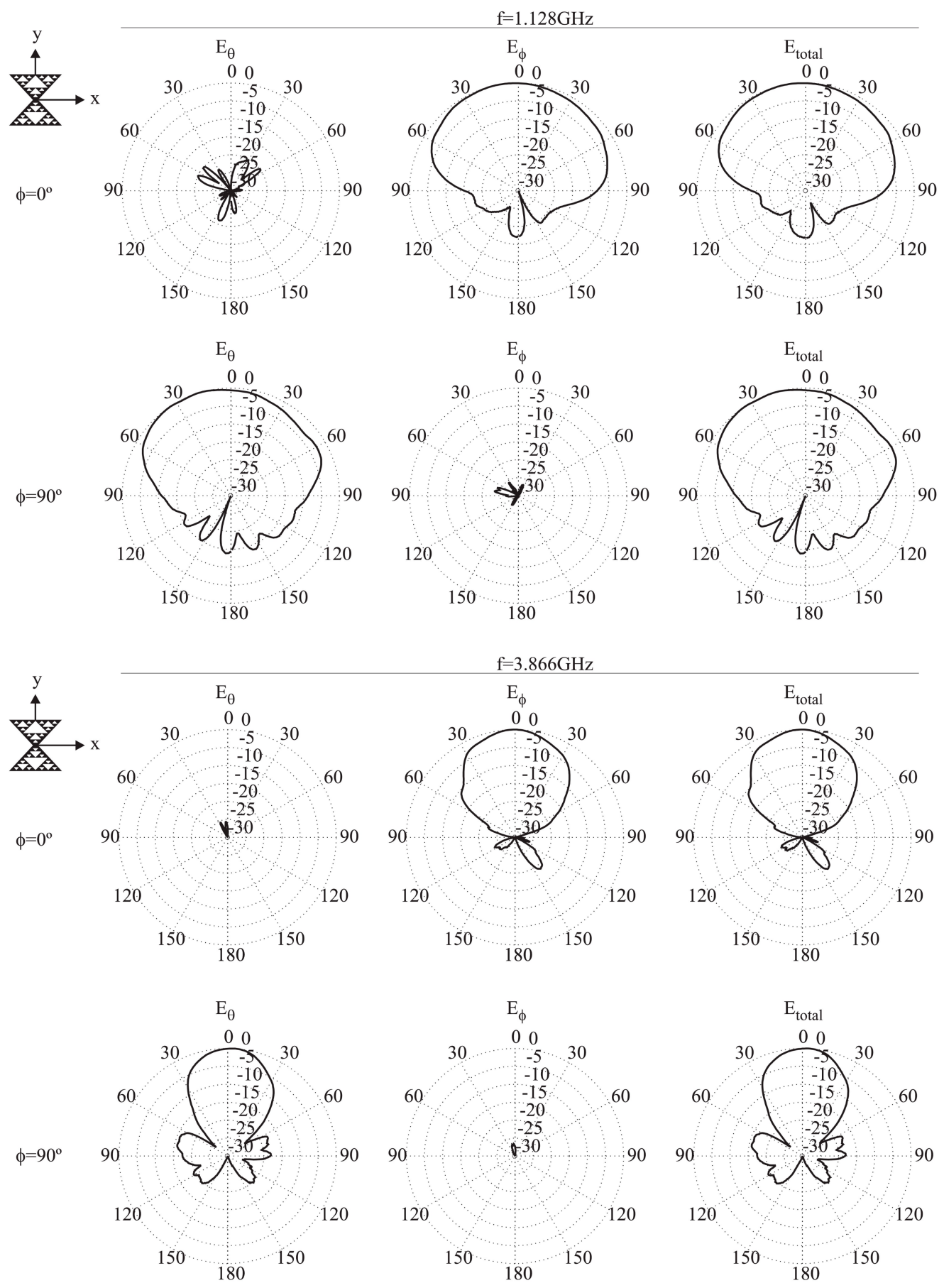

Figure 11. Measured radiation patterns for the fundamental mode and a high-directive mode of the Sierpiński antenna of Figure 10.

\subsection{Koch}

Niels Fabian Helge von Koch is a Swedish Mathematician (Stockholm 1870-Danderyn 1924) who gave fundamental contributions to the theory of differential equations, the approximation theory, and the number theory (Figure 12). In 1904, he discovered one of most famous continuous nowhere differentiable fractal curves (named after him), also known as the snowflake fractal. He studied at the University of Stockholm in 1887 under G. Mittag-Leffler and received the P.D. in Uppsala (1892). He taught pure mathematics at the KTH 1905 (succeeding Ivar Bendixon) and at the Stockholm University (since 1911). 


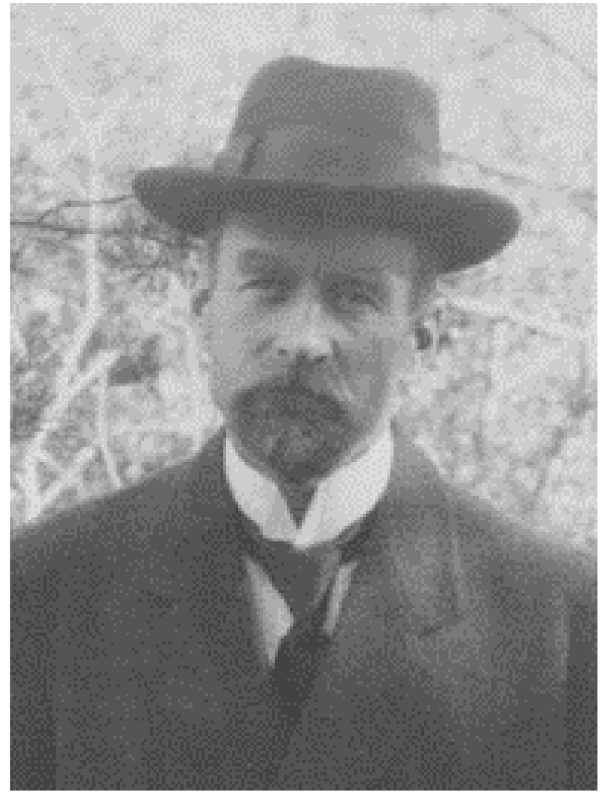

Figure 12. Niels Fabian Helge von Koch (1870-1924), Swedish mathematician. The Kock snowflake is one of the most well-known fractals.

In this section, another example of a fractal-boundary antenna is presented having a high-directivity mode (Figure 13). The microstrip patch antenna uses the Koch island and has the particularity that is printed on a hard foam. This makes this antenna very low weight $[33,58]$.

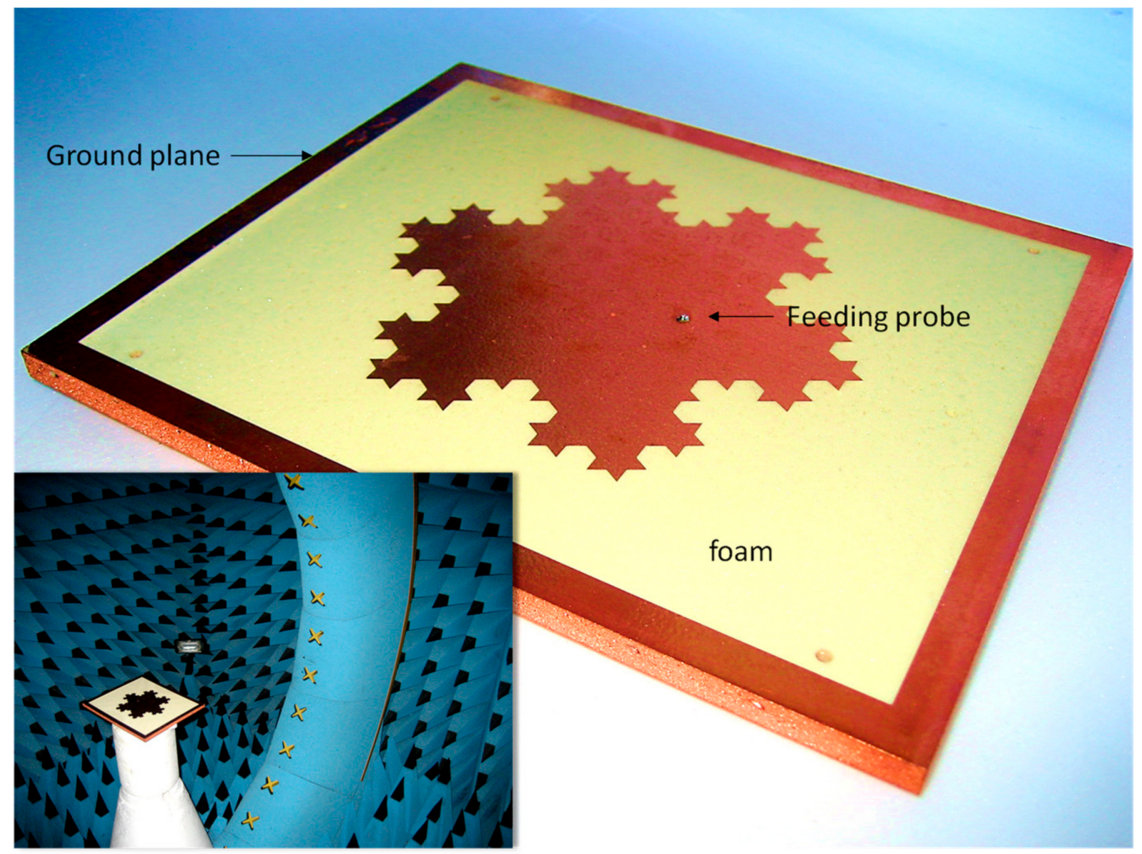

Figure 13. A microstrip patch antenna based on Koch island printed on a foam substrate presenting very low weight.

The Koch island shown on Figure 13 can be generated using an IFS as follows (Table 1):

$$
V[A]=\bigcup_{n=1}^{7} v_{n}(A)
$$


Table 1. Affine linear transformations to generate the Koch island of Figure 13.

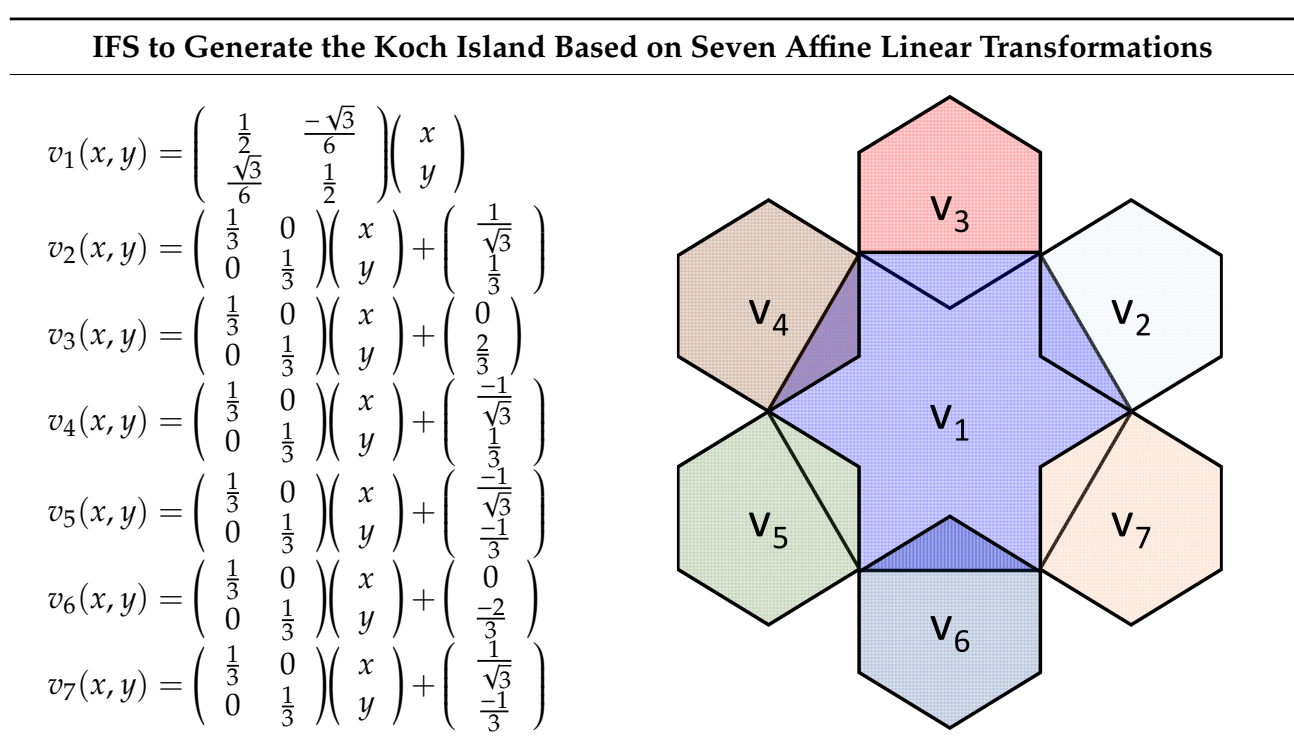

Directivity is measured along a wide frequency range where it is again observed the existence of a higher-order mode with a larger directivity compared to the fundamental mode and keeping a broadside pattern (Figure 14). It is observed that the fundamental mode $(1.1 \mathrm{GHz})$ presents a broadside radiation pattern with a moderate directivity $(8.6 \mathrm{~dB})$, whereas at the higher-order mode at $3.75 \mathrm{GHz}$, directivity increases to $13.5 \mathrm{~dB}$, keeping a broadside radiation pattern. As stated with the Mandelbrot and Sierpiński antenna, having a broadside radiation pattern with a high-directivity makes the antenna design useful, since an array is not needed and the feeding is simple since no feeding network is required, simplifying the mechanics of the antenna and also any alteration on the radiation patterns due to the radiation from the feeding network.

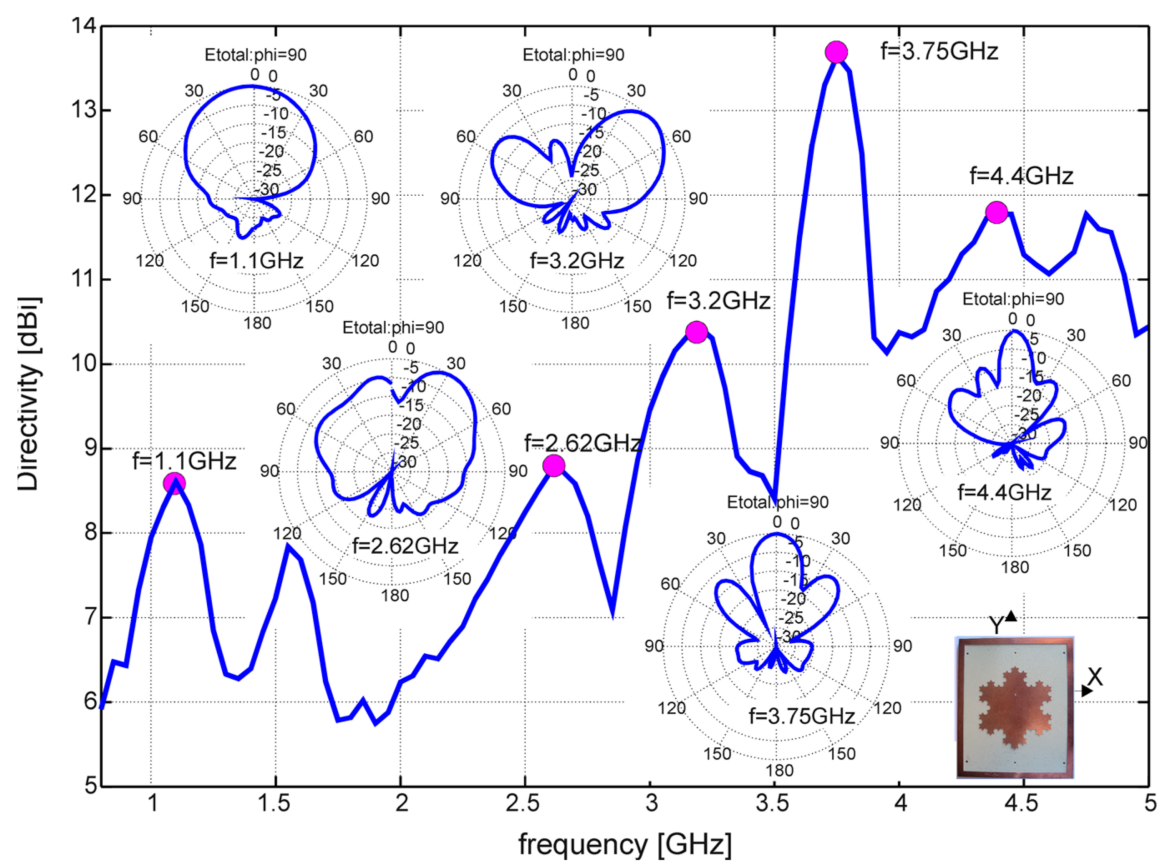

Figure 14. Measured directivity for the microstrip patch antenna of Figure 13 where the high-directive pattern is found at $3.75 \mathrm{GHz}$ [33]. 
Other structures based on the Koch island using stacked patch structures have been proposed [59]-(Figure 15).

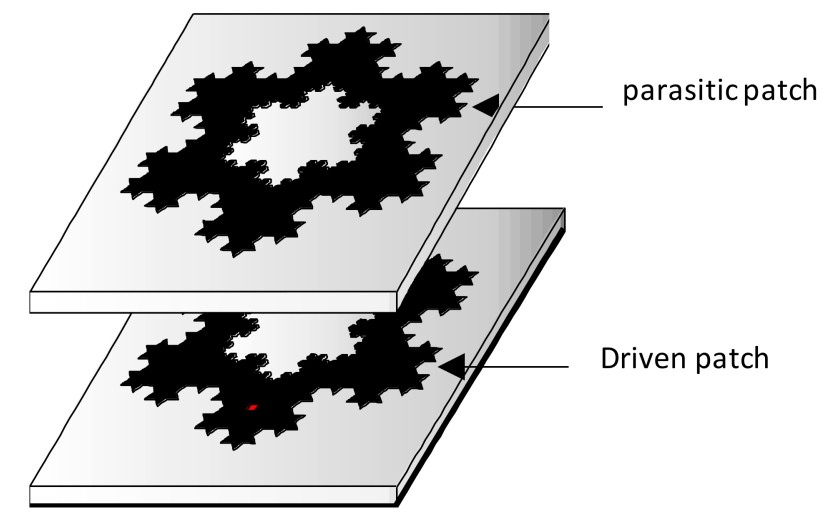

Figure 15. A microstrip antenna using a Koch-based contour comprising a two-layer structure.

On one hand, miniaturization is achieved thanks to the fractal-based patterns. On the other hand, a parasitic patch is placed above a driven patch to obtain competitive bandwidth. Since the bandwidth of a microstrip patch antenna depends on its height, a simple way to enhance the bandwidth is to collocate the patch at a certain height over the ground plane. However, in some particular cases, the radiation patterns are tilted as well, as it needs a long feeding probe which may complicate the mechanic of the antenna. On the contrary, a stacked structure provides the required bandwidth as a single patch by feeding only the driven patch. This makes the feeding much easier. Besides, the radiation patterns are more stable across the band.

Small monopole antennas based on the Koch curve have also been analyzed and compared to linear monopoles [60-62]. Slot antennas based on the Koch fractal, UWB, and energy harvesting applications have been also analyzed in [63-70].

\subsection{Hilbert}

David Hilbert, (Köninsberg 1862-Göttingen 1943) is a German mathematician who gave fundamental contributions to several fields of mathematics (geometry, analysis, logic, number theory) and physics (general relativity, quantum mechanics)—(Figure 16).

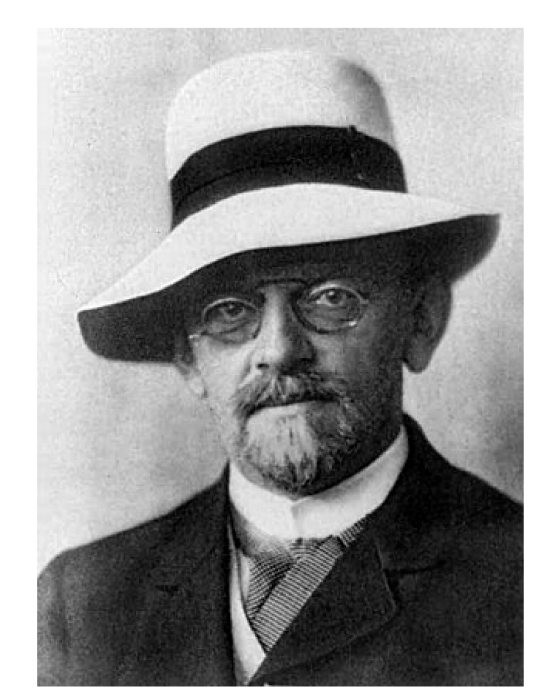

Figure 16. David Hilbert (1862-1943), German mathematician. The Hilbert curve has been used to design small antennas for wireless applications due to its space-filling properties. 
In particular, he is considered one of the founders of functional analysis. He has been professor in the University of Köninsberg (1886-1895) and in the University of Göttingen from 1895 till retirement (1930).

At the beginning of the 20th Century, he became famous also for his list of 23 (most of them still unsolved) mathematical problems, that was given at the International Congress of Mathematicians in Paris (1900).

One year after Peano, he also proposed (1891) a continuous curve filling a square, thus opening new perspectives in the pioneering search for fractals. Hilbert curve can be created by sophisticating the MRCM where two Hutchinson operators are used, resulting in a networked MRCM [9]. From a more practical perspective, a Hilbert curve can be easily constructed by creating its vertices and connecting them [71].

The space-filling properties of some fractal-inspired curves have been useful to design small antennas [62,72-81] as well as artificial magnetic conductors, which are attractive surfaces to place antennas close to a surface as well as metamaterials [82-84]. In this regard, a monopole antenna following a Hilbert pattern shows a reduction of the resonant frequency as the number of iteration increases (Figure 17). The straight monopole resonates at $799 \mathrm{MHz}$, whereas the 5th iteration of the Hilbert-base antenna resonates at $71.7 \mathrm{MHz}$. This results in a size reduction of about ten times, which is useful to design small antennas as shown next.

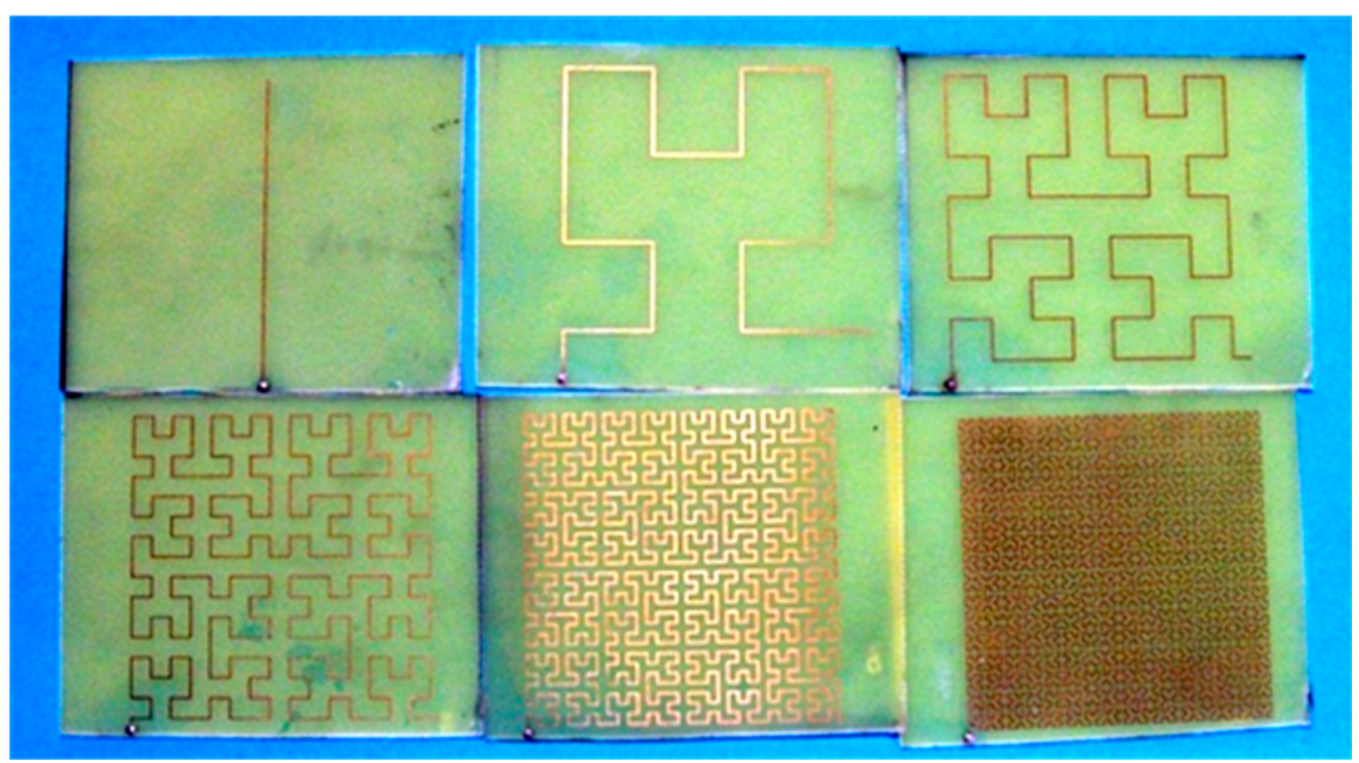

Figure 17. Several iterations of the Hilbert curve to generate a monopole: From the straight monopole $(7 \mathrm{~cm})$ to the 5 th iteration. Feed point is shown at the base. All antennas are mounted vertically on a ground plane $80 \mathrm{~cm} \times 80 \mathrm{~cm}$ [62].

Following the space-filling properties inspired in the Hilbert fractal, a small antenna for dual-band performance at WiFi $2.5 \mathrm{GHz}$ and $5 \mathrm{GHz}$ shows a total volume of only $7 \mathrm{~mm} \times 3 \mathrm{~mm} \times 2 \mathrm{~mm}$. This represents a maximum dimension of $\sim \lambda / 18$ at $2.4 \mathrm{GHz}$, which is smaller than a classical $\lambda / 4$ monopole antenna (Figure 18). 


\section{A}

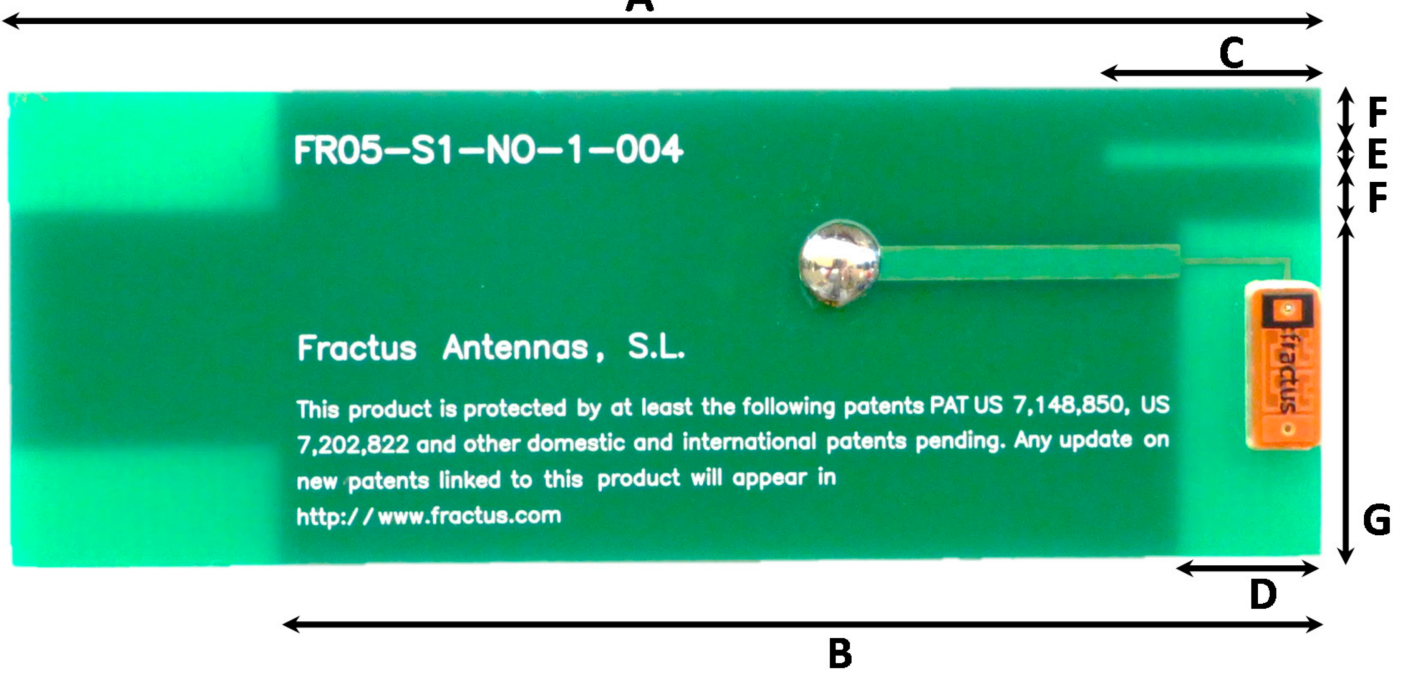

Figure 18. A very small antenna inspired in the Hilbert curve. The antenna operates a WiFi $2.5 \mathrm{GHz}$ and $5 \mathrm{GHz}$ bands within a reduced space of $7 \mathrm{~mm} \times 3 \mathrm{~mm} \times 2 \mathrm{~mm} . \mathrm{A}=55.4, \mathrm{~B}=44.2, \mathrm{C}=9.2, \mathrm{D}=6.0$, $\mathrm{E}=0.0, \mathrm{~F}=2.4, \mathrm{G}=14.3$, all cotes in $\mathrm{mm}$. Clearance area is $\mathrm{D} \times \mathrm{G}$.

Besides being small in size, the antenna presents a competitive performance for WiFi $2.5 \mathrm{GHz}$ and $5 \mathrm{GHz}$ bands, both in terms of VSWR (Voltage Standing Wave Ratio) as well as in total efficiency (Figure 19). This makes the antenna convenient for being integrated into smartphones, headsets, smartwatches, and similar wireless devices.

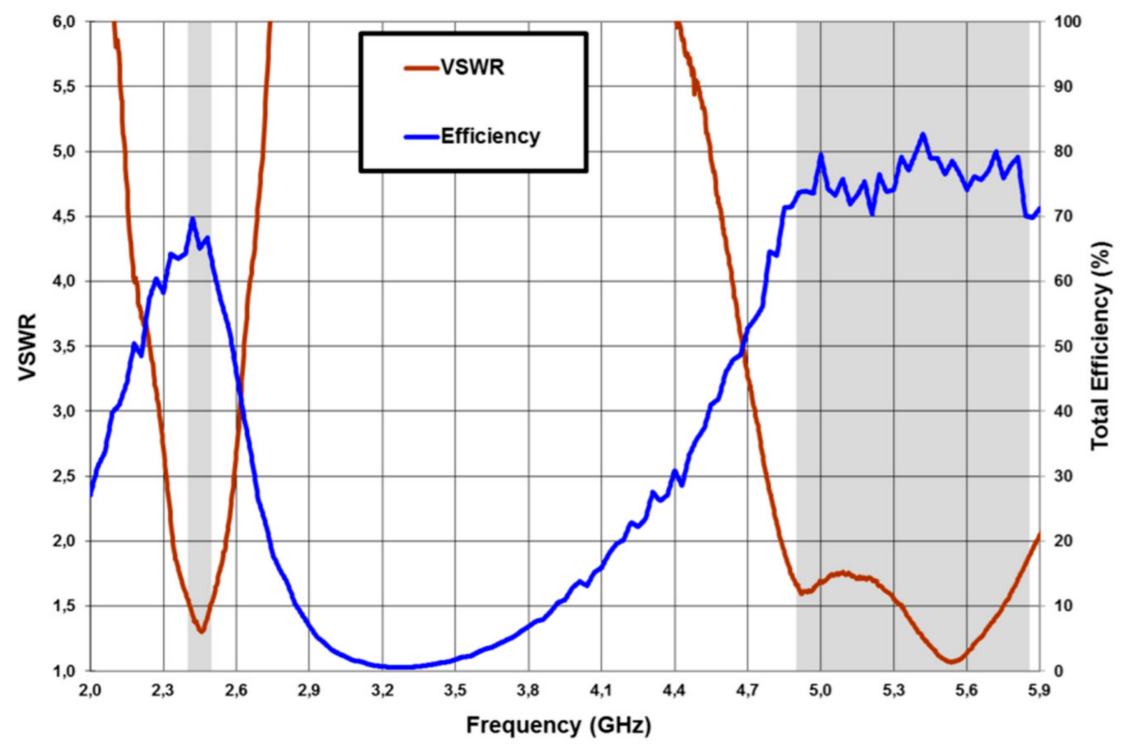

Figure 19. Measured VSWR (Voltage Standing Wave Ratio) and total efficiency for the antenna shown in Figure 18.

\subsection{Cantor}

Georg Ferdinand Ludwig Phillip Cantor is one of the most famous Mathematicians (Saint Petersburg 1845-Halle 1918) - (Figure 20). Born in Russia, in 1856 he moved to Germany where he spent almost all his life. One of his major achievements was to recognize the different cardinality of number infinite sets. Thanks to this, he was able to define a hierarchy of infinite sets, which is a fundamental property of his set theory (1874-1884). For this, he is considered the founder of a fundamental branch of mathematical research. He has been the first to propose that the infinite can be 
considered as a measurable object, so that different infinite sets might have different measures. Since 1884, he suffered for depression, and he felt some relief from philosophical and religious studies by aiming to explain better the concept of infinity as a superior entity. In 1899, because of his youngest son's death, his depression increased, thus obliging him to seek temporary retirement from teaching. During the word war, he suffered for starvation and was convicted in a psychiatric hospital where he died (1918). His main contribution to fractals is the Cantor ternary set of points lying in the unit interval. Discovered by the Irish Mathematician Henry John Stephen Smith in 1874, this set was deeply analysed by Cantor, who showed that it is a nowhere dense perfect set.

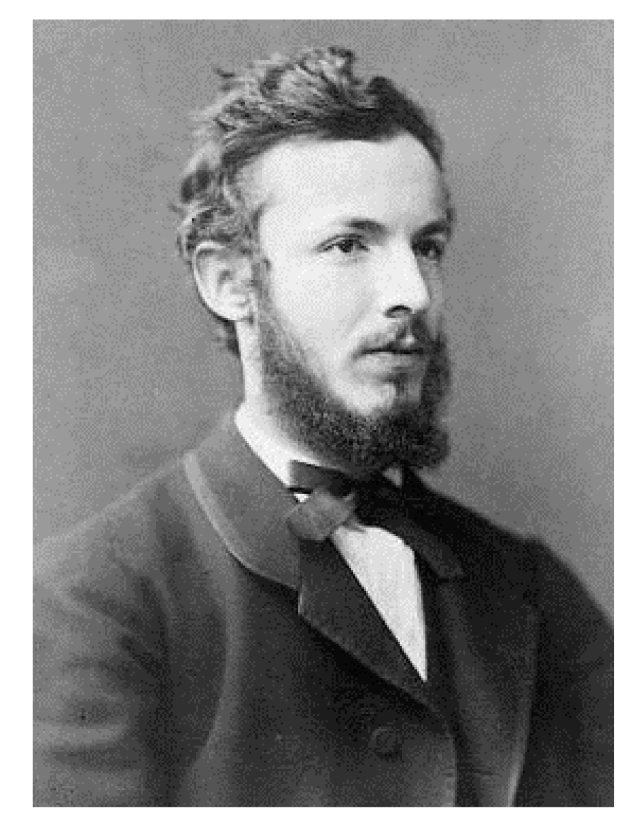

Figure 20. Georg Ferdinand Ludwig Philipp Cantor (1845-1918), German mathematician.

The Cantor set can be generated using an IFS as follows:

$$
V[A]=\bigcup_{n=1}^{2} v_{n}(A)
$$

where the affine linear transformation is defined by:

$$
\begin{aligned}
& v_{1}(x)=\frac{x}{3} \\
& v_{2}(x)=\frac{x}{3}+\frac{2}{3}
\end{aligned}
$$

The concept of multifractal refers to a geometry with multiple fractal dimensions, usually greater than one. This strategy of multi-fractal dimension is demonstrated using a Cantor set, and the corresponding fabricated prototype is presented in [85]. As the iteration progressed from $\mathrm{K}_{0}$ to $\mathrm{K}_{3}$, the antenna started covering the lower bands, which include personal and commercial communication applications.

A typical method of a planar array design with the objective of sidelobe level suppression and desired beam-width using the Cantor set is presented in [86]. The technique involves spacing the circles in the concentric ring array non-uniformly in accordance with the width of the lines of stage 4 Cantor set.

In [87], a Cantor geometry-based antenna is designed for RF energy harvesting (Figure 21). The obvious advantage of inherent multiband characteristics due to self-repetitive and self-complementary features of the Cantor set are well utilized to cover three GSM bands. In addition to this, the geometry favors fabrication using the economically viable technique like inkjet printing. 

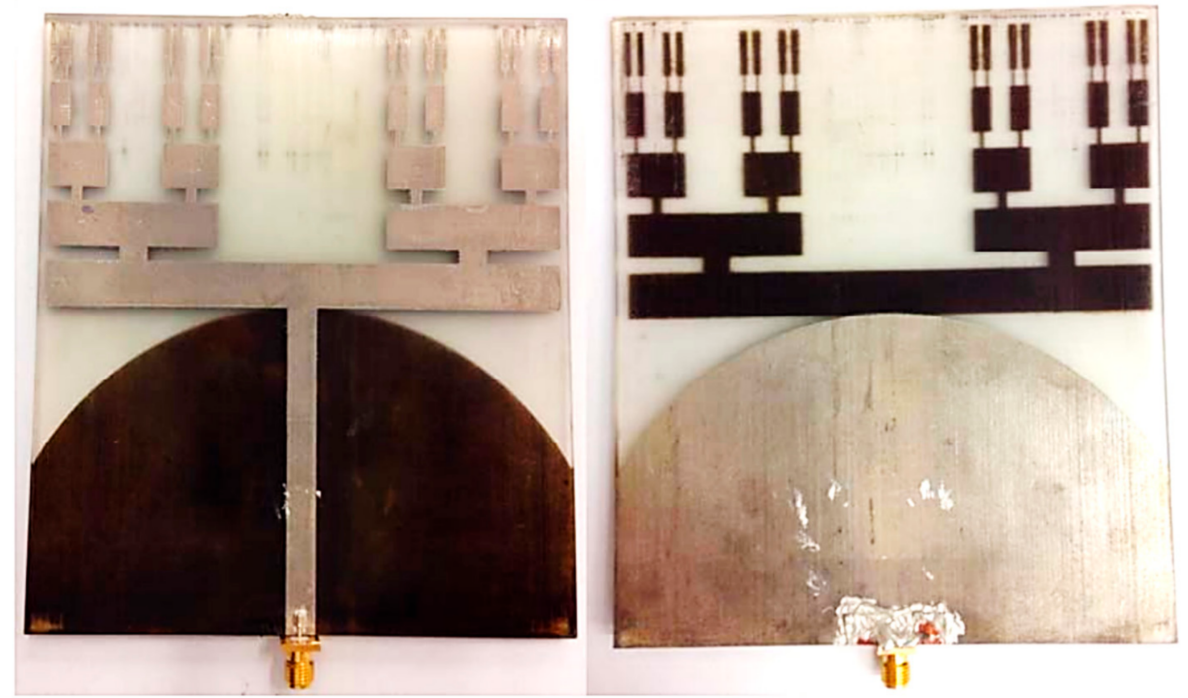

Figure 21. Cantor geometry-based antenna is designed for RF energy harvesting [87].

\subsection{Minkowski}

Hermann Minkowski, (Aleksotas (Kaunas) 1864-Göttingen 1909) was a German Mathematician born in Lithuania (as a part of the former Russian Empire)—(Figure 22). He studied Mathematics in Berlin and Königsberg, and taught in Bonn (1887), Königsberg (1894), Zurich (1896), and Göttingen (1902), sharing his original ideas and works with close friends like D. Hilbert and A. Hurwitz. Among his students, in Zurich, there was Albert Einstein, who was deeply influenced by the pioneeristic model on the non-Euclidean four-dimensional space-time proposed by Minkowski (1907). He deeply contributed to several fundamental topics of mathematics and physics like geometry of numbers, non-Euclidean geometry, quadratic forms theory, continued fractions, relativity. It was thanks to Minkowski (and G. Bouligand) that we got the definition of fractal dimension by applying the box counting algorithm.

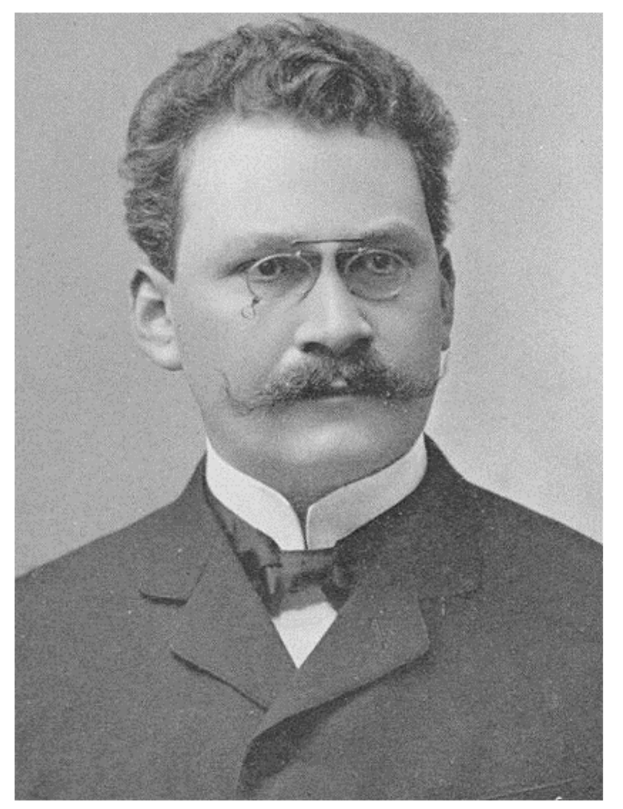

Figure 22. Hermann Minkowski (1864-1909), German mathematician. 
Minkowski fractal can be generated using an IFS as follows:

$$
V[A]=\bigcup_{n=1}^{5} v_{n}(A)
$$

where the affine linear transformation is defined by (Figure 23):

$$
\begin{aligned}
& v_{1}(x, y)=\left(\begin{array}{ll}
\frac{1}{3} & 0 \\
0 & \frac{1}{3}
\end{array}\right)\left(\begin{array}{l}
x \\
y
\end{array}\right) \\
& v_{2}(x, y)=\left(\begin{array}{ll}
\frac{1}{3} & 0 \\
0 & \frac{1}{3}
\end{array}\right)\left(\begin{array}{l}
x \\
y
\end{array}\right)+\left(\begin{array}{c}
\frac{1}{3} \\
\frac{1}{3}
\end{array}\right) \\
& v_{3}(x, y)=\left(\begin{array}{ll}
\frac{1}{3} & 0 \\
0 & \frac{1}{3}
\end{array}\right)\left(\begin{array}{l}
x \\
y
\end{array}\right)+\left(\begin{array}{c}
\frac{1}{3} \\
\frac{-1}{3}
\end{array}\right) \\
& v_{4}(x, y)=\left(\begin{array}{ll}
\frac{1}{3} & 0 \\
0 & \frac{1}{3}
\end{array}\right)\left(\begin{array}{l}
x \\
y
\end{array}\right)+\left(\begin{array}{c}
\frac{-1}{3} \\
\frac{1}{3}
\end{array}\right) \\
& v_{5}(x, y)=\left(\begin{array}{ll}
\frac{1}{3} & 0 \\
0 & \frac{1}{3}
\end{array}\right)\left(\begin{array}{l}
x \\
y
\end{array}\right)+\left(\begin{array}{c}
\frac{-1}{3} \\
\frac{-1}{3}
\end{array}\right)
\end{aligned}
$$

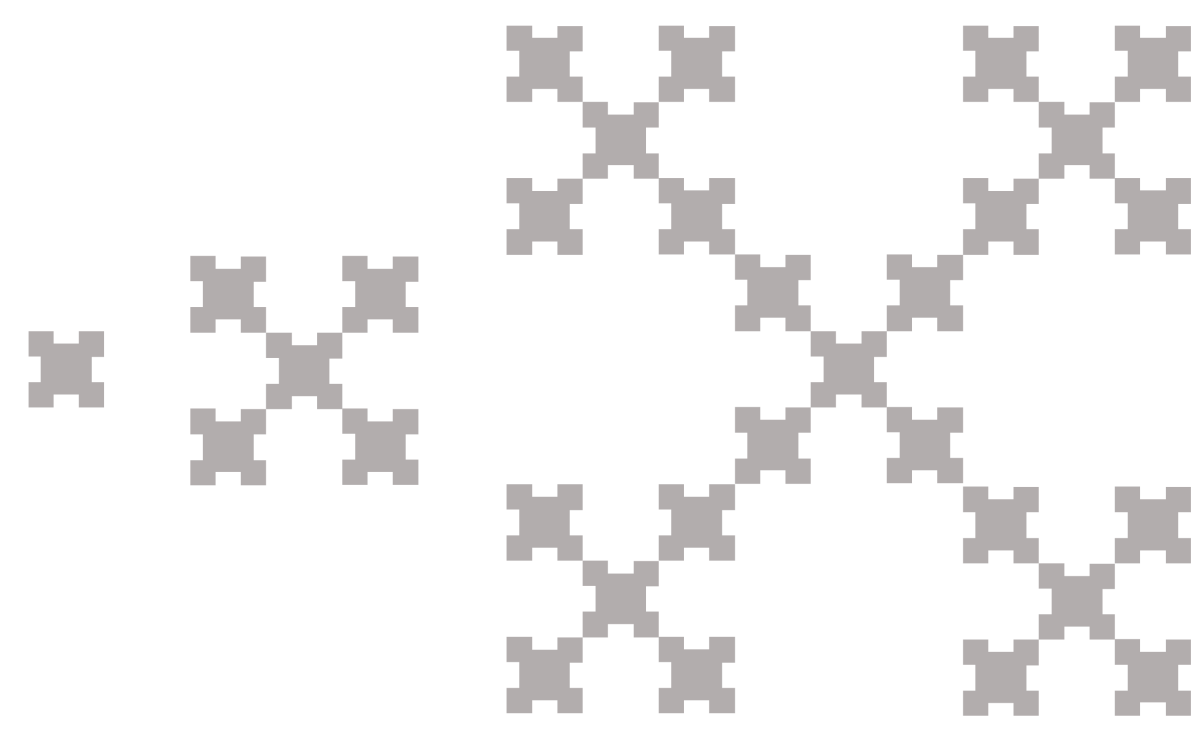

Figure 23. From the original set A to the 2nd iteration of the Minkowski fractal.

One can obtain the Minkowski fractal iterating infinitely the subset A in the following way:

$$
A_{n}=V\left[A_{n-1}\right]
$$

In this particular case, the set A (Figure 23) comprises five squares following a different pattern than the one shown in the affine transformations.

Dhar et al. [88] designed a CPW fed hepta-band antenna by incorporating Minkowski fractals. Good gain and an enhancement in the impedance bandwidth is achieved using a dielectric load. In [89], a Minkowski fractal geometry was utilized with the end goal of studying the effect of dielectric resonators on antenna bandwidth enhancement. The use of Minkowski fractals resulted in an impedance bandwidth of $64 \%$ and stable gain responses in comparison to Serpinski and Koch fractals. The miniaturization capability and resonant behavior of Minkowski fractal dipole antenna is investigated by Comisso [90]. The tortuosity of the Minkowski antenna is modelled by the incorporation of inductors. Additionally, it was observed by Comisso [90] that a justified comparison between different fractal geometries can be performed by using lacunarity as an evaluation parameter over fractal dimension. 
Vinoy et al. [91] replaced the sides of a square ring antenna with fractal Minkowski curves to achieve size miniaturization and dual band operation. The replacement resulted in $42 \%$ reduction in area as compared to its equivalent counterpart (square antenna). Zhang et al. [92] designed a frequency selective absorber exhibiting dual band polarization using Minkowski loops and lumped resistors (Figure 24). Small square loops at the four corners of the Minkowski loop resulted in parallel resonance, thereby generating passband, whereas absorptive bands were generated by series resonance of small loops, large loops, and the resistors.
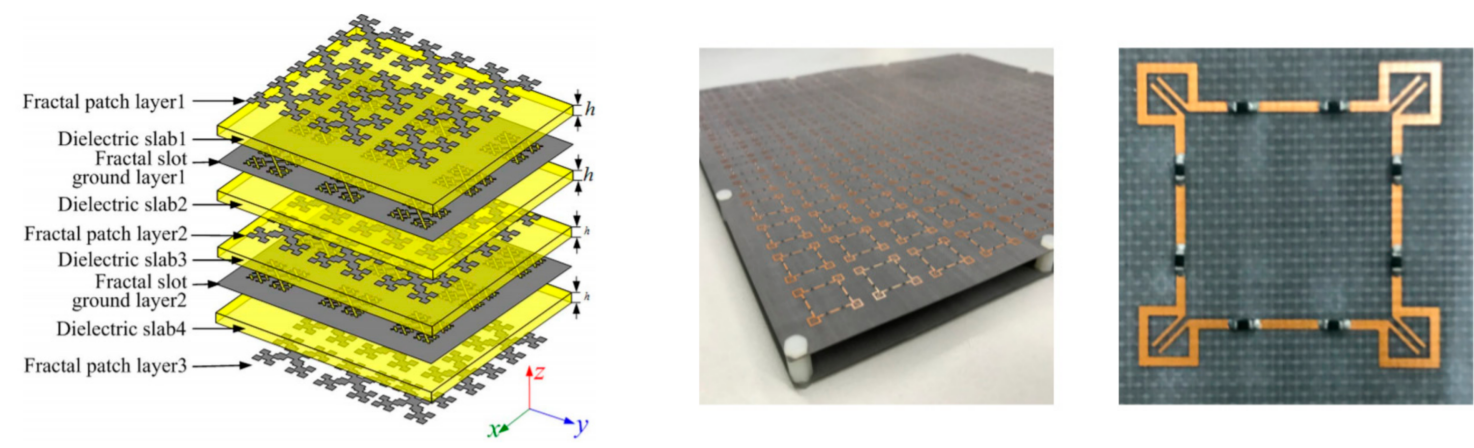

Figure 24. Left Multifrequency selective surface [92,93].

Interesting future lines combine fractals with metamaterials for improving the performance of antennas such the application shown in using a Minkowski patch antenna [94]. The unusual behavior of metamaterial (such as negative permeability, permittivity, etc.) when combined with fractal geometry results in various antenna property improvements such as size miniaturization, multiband operation, isolation enhancement between the antenna elements, etc. Literature reports numerous metamaterial-based fractal antennas to achieve the aforementioned enhancement in the antenna design [95-98]. In [95], authors employ the combined technique of metamaterial and fractal geometry to achieve antenna miniaturization and multiband operation. The optimized Minkowski fractal geometry with complimentary split ring resonator as metamaterial is used to achieve $67 \%$ size reduction in contrast with the conventional patch antennas and triple band resonance at 1.91/2.44/3.09 GHz. In [96], a decoupling metamaterial structure combined with fractal electromagnetic band gap structure is utilized to achieve isolation enhancement between $2 \times 2$ antenna arrays. The metamaterial structure was inserted between the four interconnected Y-shaped slots. A combination of chiral metamaterial with dendrite fractal geometry is employed in [97] to achieve miniaturization in overall antenna design. In [98] a compact fractal-based metamaterial antenna is utilized to achieve miniaturization and tri-wideband phenomenon. Additionally, the proposed Sierpiński-Minkowski fractal combination loaded with metamaterial resulted this structure as perfect absorber at lower frequency.

\subsection{Peano}

Giuseppe Peano was an Italian Mathematician (Spinetta di Cuneo 1858-Cavoretto 1932) who gave fundamental contributions to Analysis, Logic, and Algebra (Figure 25). His attempts to define an international scientific language (1890-93) lead him to define the fundamentals of the modern mathematical logic and set theory. Peano has been the first one to use the symbols of "union" $U$ and "intersection" $\cap$ of sets, as well as the subset symbol $\supset$ and many other symbols nowadays universally accepted such as "belongs to" $\in$ and "exists" $\exists$. In particular, thanks to Peano's Axioms (1889), we can build the arithmetic theory of natural numbers as an axiomatic hypothetic-deductive system by using the inductive principle. Peano had a strong influence on Bertrand Russell and Alfred North Whitehead, who used the Peano's axiomatization to develop the symbolic logic and the type theory. He also gave a fundamental contribution to fractals by defining (in 1890) a continuous curve (named after him) with infinite singularities that fills a square. 


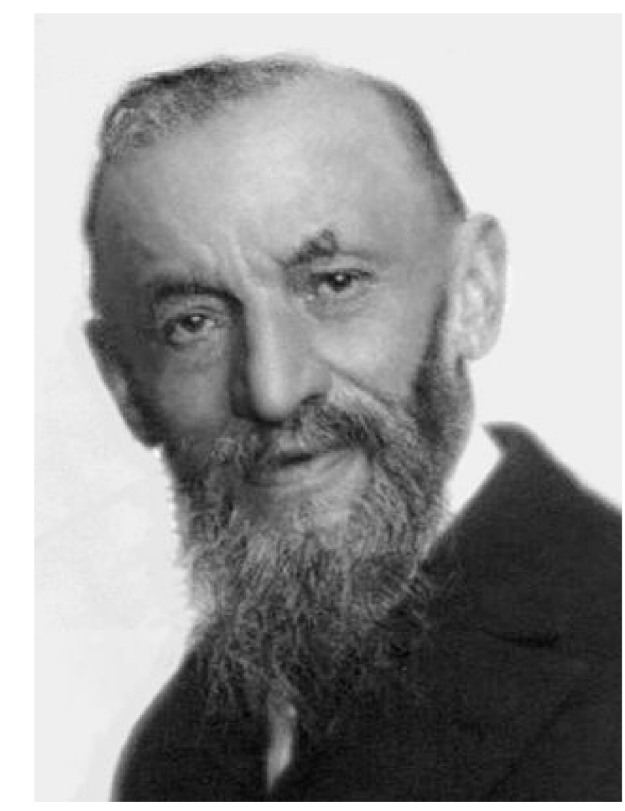

Figure 25. Giuseppe Peano (1858-1932), Italian mathematician.

The Peano curve can be generated following the same procedure as the one described for the Hilbert curve in Section 3.3.

The Peano curve inspired antenna engineers to design either small antennas, high-directive elements, arrays, and frequency selective surfaces [99-109]. A high directivity antenna with a very narrow bandwidth based on a second iteration Peano space-filling curve is proposed in [99]-(Figure 26a). It has been modified such that the final antenna operates as an array of dipoles having the same current phases. The advantage of this architecture is its simplicity, since it does not need an array of antennas and the feeding network to achieve a high-directive radiation pattern reaching $18.6 \mathrm{~dB}$. This simplifies the mechanics of the antenna as the ones presented using high-directive modes using the Sierpiński triangle and Koch island microstrip patch antennas [25-33].

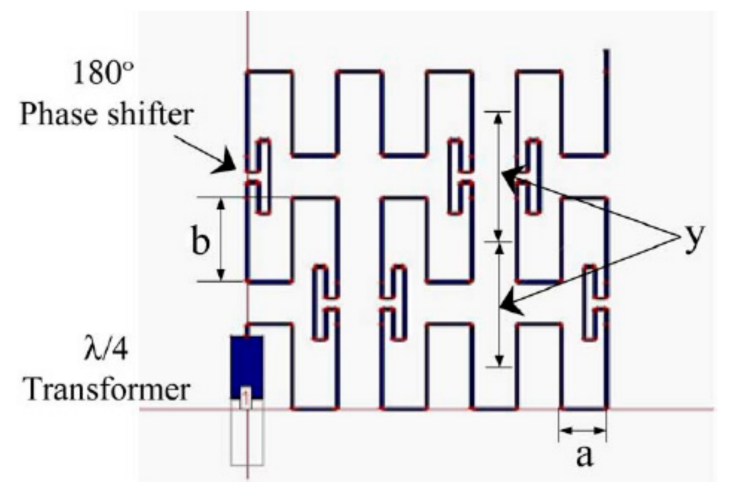

(a)

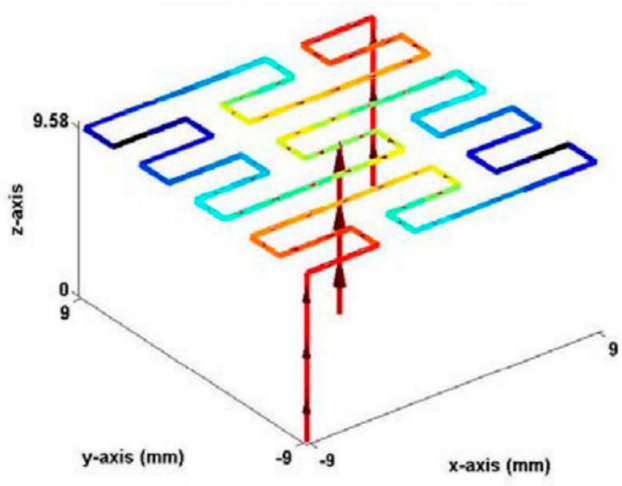

(b)

Figure 26. (a) A high-directive wire antenna above a ground plane [99]; (b) a small monopole antenna above a ground plane [100].

Use of Peano and Hilbert curves as top-loads for miniaturization of monopole antennas is proposed in [101]-(Figure 26b). It has a height of about $0.08 \lambda$, and a perfect monopolar radiation pattern. Use of Peano pre-fractal patch elements to design frequency selective surfaces (FSSs) is proposed in [104]. This approach is suitable to design compact FSSs that behave like dual-polarized band-stop spatial filters with multiband responses, dual-polarization, excellent angular stability, and facility for 
reconfiguration. Different combinations of fractal geometries were also proposed for the design of antennas for applications such as WLAN and UWB. An omnidirectional radiation pattern, a good gain, and high efficiency performances were obtained by shaping the edges of a monopole square patch antenna into the form of a Giusepe Peano fractal and its surface area as a Sierpiński carpet fractal [101]. Peano-Gosper fractal arrays, in which the array elements are uniformly distributed along a Peano-Gosper curve, to get a planar array configuration with parallelogram cells that is bounded by a closed Koch curve, is presented in [102]. They have a higher bandwidth than conventional periodic planar arrays with square or rectangular cells and regular boundary contours. Further, they possess no grating lobes even for minimum element spacings of at least one wavelength. Peano antennas have been numerically studied and compared with those of the Hilbert antennas in [103]. It was shown that a Peano antenna can be matched to a 50- or 75-ohm line for various iterations. According to the analysis done on a given patch footprint, the Peano antenna has a lower fundamental resonant frequency, resulting in an electrically more compact radiator than a comparable Hilbert antenna and a fixed-iteration order, but at the expense of a smaller input-impedance bandwidth. On the other hand, for a given electrical footprint, a Peano antenna of a lower iteration resonates at an approximately the same fundamental frequency and has a comparable bandwidth as of a higher order Hilbert antenna. The Peano antenna, however, has the advantage of having a much smaller cross-polarization level than the Hilbert antenna.

\section{Evolution of Publications in the Fractal Antenna Field}

This section illustrated the evolution of the number of publications in the field of fractal antennas (Figure 27). To obtain the presented data, the following criteria has been followed: IEEE Xplorer using the keyword fractal antenna has been used. The data base of IEEE automatically provides the number of papers divided by journals and conferences.

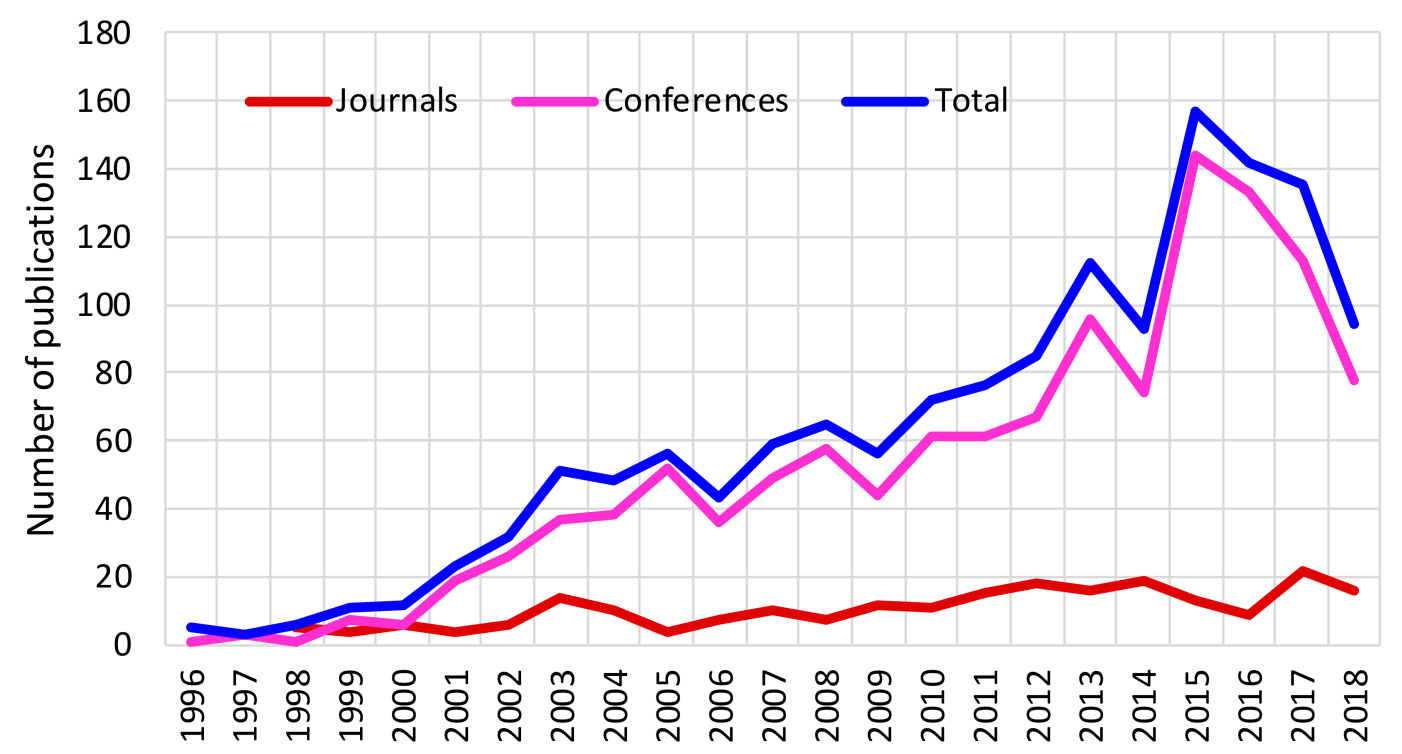

Figure 27. Evolution of the number of publications based on IEEE Xplorer.

It is significant that number of publications have significantly increased in conferences, but not in journals. Therefore, since journals usually require a higher novelty standard, it seems that not many new ideas are appearing in the scene.

\section{Conclusions}

Fractal geometry has been proven to be useful in the design of small and multiband antennas and arrays, as well in the design of high directive elements without the need of an array of antennas. Besides 
the initial work in the fundamental aspects of fractal in antenna engineering, many inspired designs based on fractals have been used to design small and compact antennas for wireless applications.

Author Contributions: J.A., A.A., and J.J. prepared Sections 1 and 3. V.V.S.S.C. and P.S.R.C. prepared Section 2 and reviewed the mathematical part of the paper. J.L.P. analyzed the bibliographic data at Section 4. T.A. contributed with the contents of fractals with metamaterials. C.C. did the biographic part and reviewed the mathematical part of the paper. All authors have read and agreed to the published version of the manuscript.

Funding: Part of the results shown in this paper received funding: MEtallized Foams In low coST Antennas, Project PROFIT no. FIT-330210-2005-103, funded by the Spanish Ministry of Industry, Tourism and Commerce (2003-2006).

Conflicts of Interest: The authors declare no conflict of interest.

\section{References}

1. Mandelbrot, B. The Fractal Geometry of Nature; W. H. Freeman and Company: San Francisco, CA, USA, 1982.

2. Werner, D.H.; Haupt, R.L.; Werner, P.L. Fractal antenna engineering: The theory and design of fractal antenna arrays. IEEE Antennas Propag. Mag. 1999, 41, 37-58. [CrossRef]

3. Gianvittorio, J.P.; Rahmat-Samii, Y. Fractal antennas: A novel antenna miniaturization technique, and applications. IEEE Antennas Propag. Mag. 2002, 44, 20-36. [CrossRef]

4. Anguera, J.; Puente, C.; Borja, C.; Soler, J. Fractal-Shaped Antennas: A Review. Encyclopedia of RF and Microwave Engineering; Chang, K., Ed.; Wiley: Chichester, NY, USA, 2005; Volume 2, pp. 1620-1635.

5. Puente, C.; Pous, R. Fractal design of multiband and low side-lobe arrays. IEEE Trans. Antennas Propag. 1996, 44, 730. [CrossRef]

6. Cohen, N. Fractal antenna applications in wireless telecommunications. In Professional Program Proceedings, Electronic Industries Forum of New England; IEEE: Boston, MA, USA, 1997; pp. 43-49.

7. Werner, D.H.; Ganguly, S. An overview of fractal antenna engineering research. IEEE Antennas Propag. Mag. 2003, 45, 38-57. [CrossRef]

8. Falconer, K. Fractal Geometry: Mathematical Foundations and Applications; John Wiley: Chichester, UK, 1990.

9. Peitgen, H.O.; Jürgens, J.; Saupe, D. Chaos and Fractals: New Frontiers of Science; Springer: Berlin / Heidelberg, Germany, 1990.

10. Minervino, D.R.; D’Assunçâo, A.G.; Peixeiro, C. Mandelbrot Fractal Microstrip Antennas. Microw. Opt. Technol. Lett. 2016, 58, 83-86. [CrossRef]

11. Silva Neto, V.P.; D’Assunção, A.G. Iterative full-wave analysis of Mandelbrot-inspired fractal patch antenna on textile substrate for UWB applications. Int. J. Antennas Propag. 2017, 2017. [CrossRef]

12. Anguera, J.; Andújar, A.; Benavente, S.; Jayasinghe, J.; Kahng, S. High-Directivity Microstrip Antenna with Mandelbrot Fractal Boundary. IET Microw. Antennas Propag. 2018, 12, 569-575. [CrossRef]

13. Puente, C.; Romeu, J.; Pous, R.; Cardama, A. On the behavior of the Sierpinski multiband fractal antenna. IEEE Trans. Antennas Propag. 1998, 46, 517-524. [CrossRef]

14. Puente, C. Fractal Antennas. Ph.D. Thesis, Universitat Politècnica de Catalunya, Barcelona, Spain, 1997.

15. Borja, C. Fractal Microstrip Patch Antennas with Fractal Perimeter and Self-Affine Properties. Ph.D. Thesis, Universitat Politècnica de Catalunya, Barcelona, Spain, 2001.

16. Anguera, J. Fractal and BroadBand Techniques for Miniature, Multifrequency and High-Directivity Microstrip Patch Antennas. Ph.D. Thesis, Universitat Politècnica de Catalunya, Barcelona, Spain, 2003.

17. Soler, J. Novel Multifrequency and Small Monopole Antenna for Wireless and Mobile Applications. Ph.D. Thesis, Universitat Politècnica de Catalunya, Barcelona, Spain, 2004.

18. Gianvittorio, J.P.; Romeu, J.; Blanch, S.; Rahmat-Samii, Y. Self-similar prefractal frequency selective surfaces for multiband and dual-polarized applications. IEEE Trans. Antennas Propag. 2003, 51, 3088-3096. [CrossRef]

19. Kim, Y.; Jaggard, D.L. The fractal random array. Proc. IEEE 1986, 74, 1278-1280. [CrossRef]

20. Puente, C.; Claret, J.; Sagues, F.; Romeu, J.; López-Salvans, M.Q.; Pous, R. Multiband properties of a fractal tree antenna generated by electrochemical deposition. IEE Electron. Lett. 1996, 32, 2298-2299. [CrossRef]

21. Rmili, H.; el Mrabet, O.; Floc'h, J.; Miane, J. Study of an Electrochemically-Deposited 3-D Random Fractal Tree-Monopole Antenna. IEEE Trans. Antennas Propag. 2007, 55, 1045-1050. [CrossRef]

22. Rmili, H.; DoniaI, O.; Trad, I.B.; Floch, J.M.; Mittra, R. Investigation of a Random-Fractal Antenna Based on a Natural Tree-Leaf Geometry. Int. J. Antennas Propag. 2017, 2017, 7. [CrossRef] 
23. Laadhar, L.; Zaraouan, M.; Oueslati, D.; Floch, J.M.; Rmili, H. Investigation on Cellular-Automata Irregular-Fractal Ultra-Wideband Slot-Antennas. Microw. Opt. Technol. Lett. 2015, 57, 2506-2514. [CrossRef]

24. Rmili, H.; Floch, R.; Zangar, H. Experimental of a 2-D Irregular fractal jet printed antenna. IEEE Antennas Wirel. Propag. Lett. 2009, 8, 328-331. [CrossRef]

25. Anguera, J.; Puente, C.; Borja, C.; Montero, R.; Soler, J. Small and High Directivity Bowtie Patch Antenna based on the Sierpinski Fractal. Microw. Opt. Technol. Lett. 2001, 31, 239-241. [CrossRef]

26. Borja, C.; Font, G.; Blanch, S.; Romeu, J. High Directivity Fractal Boundary Microstrip Patch Antenna. IEE Electron. Lett. 2000, 36, 778-779. [CrossRef]

27. Anguera, J.; Montesinos, G.; Puente, C.; Borja, C.; Soler, J. An Under-Sampled High Directivity Microstrip Patch Array with a Reduced Number of Radiating elements Inspired on the Sierpinski Fractal. Microw. Opt. Technol. Lett. 2003, 37, 100-103. [CrossRef]

28. Anguera, J.; Puente, C.; Borja, C.; Montero, R. Bowtie Microstrip Patch Antenna based on the Sierpinski Fractal. IEEE Antennas Propag. Soc. Int. Symp. 2001, 3, 162-165.

29. Montesinos, G.; Anguera, J.; Puente, C.; Borja, C. The Sierpinski fractal bowtie patch: A multifracton-mode antenna. IEEE Antennas Propag. Soc. Int. Symp. 2002, 4, 542-545.

30. Anguera, J.; Montesinos, G.; Puente, C.; Borja, C.; Soler, J. Fracton-Mode Arrays using Microstrip Fractal Sierpinski Based Radiators. In Proceedings of the Antenna Systems 2003, Denver, CO, USA, 8-9 October 2003.

31. Anguera, J.; Montesinos, G.; Puente, C.; Borja, C.; Soler, J. Scanning properties in fracton-mode microstrip arrays using elements inspired on the Sierpinski fractal. In Proceedings of the IEEE Antennas and Propagation Society International Symposium, Monterey, CA, USA, 20-26 June 2004.

32. Anguera, J.; Puente, C.; Borja, C.; Soler, J. Scanning properties in an under-sampled microstrip array using Sierpinski fractal-inspired elements. In Proceedings of the 27th ESA Antenna Technology Workshop on Innovative Periodic Antennas, Santiago de Compostela, Spain, 9-11 March 2004.

33. Anguera, J.; Daniel, J.P.; Borja, C.; Mumbru, J.; Puente, C.; Leduc, T.; Laeveren, N.; Van Roy, P. Metallized Foams for Fractal-Shaped Microstrip Antennas. IEEE Antennas Propag. Mag. 2008, 50, 20-38. [CrossRef]

34. Anguera, J.; Borja, C.; Puente, C. Microstrip Fractal-Shaped Antennas: A Review. In Proceedings of the EUCAP Second European Conference on Antennas and Propagation, Edinburgh, UK, 11-16 November 2007.

35. Song, C.T.P.; Hall, P.S.; Ghafouri-Shiraz, H.; Wake, D. Sierpinski Monopole Antenna with Controlled Band Spacing and Input Impedance. IEE Electron. Lett. 1999, 35, 1036-1037. [CrossRef]

36. Romeu, J.; Rahmat-Samii, Y. Fractal FSS: A novel dual-band frequency selective surface. IEEE Trans. Antennas Propag. 2000, 48, 1097. [CrossRef]

37. Soler, J.; Puente, C.; Anguera, J. Extended multiperiodic traveling wave model for the accurate analysis of the radiation performance of the Sierpinski fractal-like multiband antenna. Microw. Opt. Technol. Lett. 2003, 36, 67-70. [CrossRef]

38. Puente, C.; Romeu, J.; Bartolome, R.; Pous, R. Perturbation of the Sierpinski antenna to allocate operating bands. Electron. Lett. 1996, 32, 2186-2188. [CrossRef]

39. Anguera, J.; Martínez, E.; Puente, C.; Borja, C.; Soler, J. BroadBand Dual-Frequency Microstrip Patch Antenna with Modified Sierpinski Fractal Geometry. IEEE Trans. Antennas Propag. 2004, 52, 66-73. [CrossRef]

40. Borja, C.; Puente, C.; Romeu, J.; Anguera, J. Fractal Multiband Patch Antenna. In Proceedings of the Millennium Conference on Antennas and Propagation AP2000, Davos, Switzerland, 9-14 April 2000.

41. Anguera, J.; Martínez, E.; Puente, C.; Borja, C.; Soler, J. Broad-Band Triple-Frequency Microstrip Patch Radiator Combining a Dual-Band Modified Sierpinski Fractal and a Monoband Antenna. IEEE Trans. Antennas Propag. 2006, 54, 3367-3373. [CrossRef]

42. Anguera, J.; Daniel, J.P.; Borja, C.; Mumbrú, J.; Puente, C.; Leduc, T.; Sayegrih, K.; van Roy, P. Metallized Foams for Antenna Design: Application to Fractal-Shaped Sierpinski-Carpet Monopole. Progress Electromagn. Res. 2010, 104, 239-251. [CrossRef]

43. Chowdary, P.S.R.; Prasad, A.M.; Rao, P.M.; Anguera, J. Simulation of Radiation Characteristics of Sierpinski Fractal Geometry for Multiband Applications. Int. J. Inf. Electron. Eng. 2013, 3, 618-621. [CrossRef]

44. Chowdary, P.S.R.; Prasad, A.M.; Rao, P.M.; Anguera, J. Design and Performance Study of Sierpinski Fractal Based Patch Antennas for Multiband and Miniaturization Characteristics. Wirel. Pers. Commun. 2015, 83, 1-18. [CrossRef] 
45. Anguera, J.; Puente, C.; Borja, C.; Romeu, J. Miniature WideBand Stacked Microstrip Patch Antenna based on the Sierpinski Fractal Geometry. In Proceedings of the IEEE Antennas and Propagation Society International Symposium, Salt Lake City, UT, USA, 16-21 July 2000; Volume 3, pp. 1700-1703.

46. Soler, J.; Puente, C.; Anguera, J. Challenges in the Numerical Analysis of Fractal-Shaped Antennas. In Proceedings of the IEEE Antennas and Propagation Society International Symposium, San Antonio, TX, USA, 16-21 June 2002.

47. Soler, J.; Puente, C.; Anguera, J. Multifrequency Properties of Monopole Antennas Using Multilevel Ground Planes Inspired on the Sierpinski Fractal Shape. In Proceedings of the IEEE Antennas and Propagation Society International Symposium, Columbus, OH, USA, 22-27 June 2003.

48. Soler, J.; Puente, C.; Anguera, J. Solutions to Tailor the Radiation Patterns of 2D and 3D Multiband Antennas Based on the Sierpinski Fractal. In Proceedings of the IEEE Antennas and Propagation Society International Symposium, Columbus, OH, USA, 22-27 June 2003.

49. Soler, J.; Puente, C.; Anguera, J. Results on a New Extended Analytic Model to Understand The Radiation Performance of Mod-P Sierpinski Fractal Multiband Antennas. In Proceedings of the IEEE Antennas and Propagation Society International Symposium, Columbus, OH, USA, 22-27 June 2003.

50. Anguera, J.; Martínez, E.; Puente, C.; Borja, C.; Soler, J. Dual-Band BroadBand Microstrip Antenna Inspired in the Sierpinski Fractal. In Proceedings of the IEEE Antennas and Propagation Society International Symposium, Monterey, CA, USA, 20-26 June 2004.

51. Anguera, J.; Borja, C.; Martínez, E.; Puente, C.; Soler, J. Dual-Frequency Microstrip Patch Antennas based on the Sierpinski Fractal. In Proceedings of the Korean 2004 Fall Microwave and Propagation Conference, Asan-Si, Korea, September 2004.

52. Anguera, J.; Martínez, E.; Puente, C.; Borja, C.; Soler, J. Triple-Band Broadband Microstrip Patch Antenna Inspired in the Sierpinski Fracta. In Proceedings of the IEEE Antennas and Propagation Society International Symposium, Washington, DC, USA, 3-8 July 2005.

53. Anguera, J.; Borja, C.; Puente, C.; Soler, J. Dual-Band Array Using Fracton-Mode Microstrip Antenna Based on Sierpinski Fractal. In Proceedings of the IEEE Antennas and Propagation Society International Symposium, Albuquerque, NM, USA, 9-14 July 2006.

54. Singhal, S.; Singh, A.K. CPW-fed hexagonal Sierpinski super wideband fractal antenna. IET Microw. Antennas Propag. 2016, 10, 1701-1707. [CrossRef]

55. Singh, A.; Singh, S. Design and optimization of a modified Sierpinski fractal antenna for broadband applications. Appl. Soft Comput. 2016, 38, 843-850. [CrossRef]

56. Sivia, J.S.; Kaur, G.; Sarao, A. Modified Sierpinski carpet fractal antenna for multiband applications. Wirel. Pers. Commun. 2017, 95, 4269-4279. [CrossRef]

57. Kingsley, N.; Anagnostou, D.E.; Tentzeris, M.; Papapolymerou, J. RF MEMS Sequentially Reconfigurable Sierpinski Antenna on a Flexible Organic Substrate with Novel DC-Biasing Technique. J. Microelectromechanical Syst. 2007, 16, 1185-1192. [CrossRef]

58. Anguera, J.; Daniel, J.P.; Borja, C.; Mumbrú, J.; Puente, C.; Leduc, T.; Laeveren, N.; van Roy, P. On the behavior of the Koch Island Fractal-Shaped Microstrip Patch Antenna etched on a Metallized Foam. In Proceedings of the IEEE Antennas and Propagation Society International Symposium, San Diego, CA, USA, 5-11 July 2008.

59. Anguera, J.; Puente, C.; Borja, C. Miniature Broadband Ring-Like Microstrip Patch Antenna. U.S. Patent 6,870,507 B2, 22 March 2005.

60. Puente, C.; Romeu, J.; Cardama, A. The Koch monopole: A small fractal antenna. IEEE Trans. Antennas and Propag. 2000, 48, 1773-1781.

61. Puente, C.; Romeu, J.; Pous, R.; Ramis, J.; Hijazo, A. Small but long Koch fractal monopole. Electron. Lett. 1998, 34, 9-10. [CrossRef]

62. Anguera, J.; Puente, C.; Martínez, E.; Rozan, E. The fractal Hilbert monopole: A two-dimensional wire. Microw. Optical Technol. Lett. 2003, 36, 102-104. [CrossRef]

63. Farswan, A.; Gautam, A.K.; Kanaujia, B.K.; Rambabu, K. Design of Koch fractal circularly polarized antenna for handheld UHF RFID reader applications. IEEE Trans. Antennas Propag. 2015, 64, 771-775. [CrossRef]

64. Yaziz, N.S.M.; Rahim, M.K.A.; Zubir, F.; Nadzir, N.S.; Dewan, R.; Majid, H.A. The Improvement of First Iteration Log Periodic Fractal Koch Antenna with Slot Implementation. Int. J. Electr. Comput. Eng. 2018, 8, 2564.

65. Choukiker, Y.K.; Behera, S.K. Wideband frequency reconfigurable Koch snowflake fractal antenna. IET Microw. Antennas Propag. 2017, 11, 203-208. [CrossRef] 
66. Rahman, N.A.A.; Jamlos, M.F.; Lago, H.; Jamlos, M.A.; Soh, P.J.; Al-Hadi, A.A. Reduced size of slotted-fractal Koch log-periodic antenna for 802.11 TVWS application. Microw. Opt. Technol. Lett. 2015, 57, 2732-2737. [CrossRef]

67. Yaziz, N.S.M.; Rahim, M.K.A.; Zubir, F.; Murad, N.A. Series iteration of Fractal Koch antenna at UHF band. In Proceedings of the 2016 10th European Conference on Antennas and Propagation (EuCAP), Davos, Switzerland, 10-15 April 2016; pp. 1-4.

68. Rajabloo, H.; Kooshki, V.A.; Oraizi, H. Compact microstrip fractal Koch slot antenna with ELC coupling load for triple band application. AEU-Int. J. Electron. Commun. 2017, 73, 144-149. [CrossRef]

69. Hebelka, V.; Velim, J.; Raida, Z. Dual band Koch antenna for RF energy harvesting. In Proceedings of the 2016 10th European Conference on Antennas and Propagation (EuCAP), Davos, Switzerland, 10-15 April 2016; pp. 1-3.

70. Gupta, M.; Mathur, V. Koch boundary on the square patch microstrip antenna for ultra wideband applications. Alex. Eng. J. 2018, 57, 2113-2122. [CrossRef]

71. Ye, R.; Liu, L. An Iterated Function System based Method to Generate Hilbert-type Space-filling Curves. Int. J. Inf. Technol. Comput. Sci. 2015, 12, 12-22. [CrossRef]

72. Gala, D.; Soler, J.; Puente, C.; Borja, C.; Anguera, J. Miniature Microstrip Patch Antenna Loaded with a Space-Filling Line Based on the Fractal Hilbert Curve. Microw. Opt. Technol. Lett. 2003, 38, 311-312. [CrossRef]

73. Anguera, J.; Puente, C.; Soler, J. Miniature Monopole Antenna based on the Fractal Hilbert Curve. IEEE Antennas Propag. Soc. Int. Symp. 2002, 4, 546-549.

74. Azad, M.Z.; Ali, M. A miniaturized Hilbert PIFA for dual-band mobile wireless applications. IEEE Antennas Wirel. Propag. Lett. 2005, 4, 59-62. [CrossRef]

75. Azaro, R.; Viani, F.; Lizzi, L.; Zeni, E.; Massa, A. A Monopolar Quad-Band Antenna Based on a Hilbert Self-Affine Prefractal Geometry. IEEE Antennas Wirel. Propag. Lett. 2009, 8, 177-180. [CrossRef]

76. Baliarda, C.P.; Rozan, E.J.L.; Anguera, J. Space-Filling Miniature Antennas. U.S. Patent 7,202,822, 10 April 2007.

77. Sanz, I.; Anguera, J.; Andújar, A.; Puente, C.; Borja, C. The Hilbert Monopole Revisited. In European Conference on Antennas and Propagation; EuCAP: Barcelona, Spain, 2010.

78. Bangi, I.S.; Sivia, J.S. Minkowski and Hilbert curves-based hybrid fractal antenna for wireless applications. AEU-Int. J. Electron. Commun. 2018, 85, 159-168. [CrossRef]

79. Saputro, S.A.; Chung, J.Y. Hilbert curve fractal antenna for dual on-and off-body communication. Prog. Electromagn. Res. 2016, 58, 81-88. [CrossRef]

80. Krim, K.; Abri, M.; Badaoui, H.; Fersiti, S.; Mahieddine, F. New Design of a Microstrip-Fed Printed Slot UWB Antenna with Hilbert Fractal Defected Ground Structure. In Third International Conference on Computing and Wireless Communication Systems; European Alliance for Innovation (EAI): Ghent, Belgium, 2019.

81. Roushdy, M.M.; Hammad, H.F. Inkjet printed wearable Hilbert monopole fractal antenna optimized for BAN systems. In Proceedings of the 2016 33rd National Radio Science Conference (NRSC), Aswan, Egypt, 22-25 January 2016; pp. 102-108.

82. McVay, J.; Engheta, N.; Hoorfar, A. High-impedance metamaterial surfaces using Hilbert-curve inclusions. IEEE Microw. Wirel. Comp. Lett. 2004, 14, 130-132. [CrossRef]

83. McVay, J.; Engheta, N.; Hoorfar, A. Numerical study and parameter estimation for double-negative metamaterials with Hilbert-curve inclusions. In Proceedings of the 2005 IEEE Antennas and Propagation Society International Symposium, Washington, DC, USA, 3-8 July 2005; Volume 2, pp. 328-331.

84. Yousefi, L.; Ramahi, O.M. Artificial Magnetic Materials Using Fractal Hilbert Curves. IEEE Trans. Antennas Propag. 2010, 58, 2614-2622. [CrossRef]

85. Manimegalai, B.; Raju, S.; Abhaikumar, V. A Multifractal Cantor Antenna for Multiband Wireless Applications. IEEE Antennas Wirel. Propag. Lett. 2009, 8, 359-362. [CrossRef]

86. Hebib, S.; Raveu, N.; Aubert, H. Cantor Spiral Array for the Design of Thinned Arrays. IEEE Antennas Wirel. Propag. Lett. 2006, 5, 104-106. [CrossRef]

87. Bakytbekov, A.; Maza, A.R.; Nafe, M.; Shamim, A. Fully inkjet printed wide band cantor fractal antenna for RF energy harvesting application. In Proceedings of the 2017 11th European Conference on Antennas and Propagation (EUCAP), Paris, France, 19-24 March 2017; pp. 489-491.

88. Dhar, S.; Patra, K.; Ghatak, R.; Gupta, B.; Poddar, D.R. A Dielectric Resonator-Loaded Minkowski Fractal-Shaped Slot Loop Heptaband Antenna. IEEE Trans. Antennas Propag. 2015, 63, 1521-1529. [CrossRef] 
89. Dhar, S.; Ghatak, R.; Gupta, B.; Poddar, D.R. A Wideband Minkowski Fractal Dielectric Resonator Antenna. IEEE Trans. Antennas Propag. 2013, 61, 2895-2903. [CrossRef]

90. Comisso, M. Theoretical and numerical analysis of the resonant behaviour of the Minkowski fractal dipole antenna. IET Microw. Antennas Propag. 2019, 3, 456-464. [CrossRef]

91. Vinoy, K.J.; Pal, A. Dual-frequency characteristics of Minkowski-square ring antennas. IET Microw. Antennas Propag. 2010, 4, 219-224. [CrossRef]

92. Li, Y.; Li, L.; Zhang, Y.; Zhao, C. Design and Synthesis of Multilayer Frequency Selective Surface Based on Antenna-Filter-Antenna Using Minkowski Fractal Structures. IEEE Trans. Antennas Propag. 2015, 63, $133-141$. [CrossRef]

93. Zhang, X.; Wu, W.; Huang, L.; Ma, Y.; Yuan, N. Design of Dual Absorptive Bands Frequency Selective Rasorber with Minkowski Loop Arrays. IEEE Antennas Wirel. Propag. Lett. 2019, 18, 1843-1847. [CrossRef]

94. Kubacki, R.; Czyzewski, M.; Laskowski, D. Minkowski Island and Crossbar Fractal Microstrip Antennas for Broadband Applications. Appl. Sci. 2018, 8, 334. [CrossRef]

95. Cao, T.N.; Krzysztofik, W.J. A Novel Design for Compact Multi-Band Antenna Based on Fractal Geometry and Metamaterials. In Proceedings of the 2019 IEEE European Microwave Conference in Central Europe (EuMCE), Prague, Czech Republic, 13-15 May 2019; pp. 171-174.

96. Alibakhshikenari, M.; Virdee, B.S.; See, C.H.; Abd-Alhameed, R.; Ali, A.H.; Falcone, F.; Limiti, E. Study on isolation improvement between closely-packed patch antenna arrays based on fractal metamaterial electromagnetic bandgap structures. IET Microw. Antennas Propag. 2018, 12, 2241-2247. [CrossRef]

97. Zarifi, D.; Soleimani, M.; Nayyeri, V.; Rashed-Mohassel, J. On the miniaturization of semiplanar chiral metamaterial structures. IEEE Trans. Antennas Propag. 2012, 60, 5768-5776. [CrossRef]

98. Amiri, M.; Tofigh, F.; Shariati, N.; Lipman, J.; Abolhasan, M. Miniature tri-wideband Sierpinski-Minkowski fractals metamaterial perfect absorber. IET Microw. Antennas Propag. 2019, 13, 991-996. [CrossRef]

99. El-Khouly, E.; Ghali, H.; Khamis, S.A. High Directivity Antenna Using a Modified Peano Space-Filling Curve. IEEE Antennas Wirel. Propag. Lett. 2007, 6, 405-407. [CrossRef]

100. McVay, J.; Hoorfar, A. Miniaturization of top-loaded monopole antennas using Peano-curves. In Proceedings of the 2007 IEEE Radio and Wireless Symposium, Long Beach, CA, USA, 9-11 January 2007; pp. 253-256.

101. Oraizi, H.; Hedayati, S. Miniaturized UWB Monopole Microstrip Antenna Design by the Combination of Giusepe Peano and Sierpinski Carpet Fractals. IEEE Antennas Wirel. Propag. Lett. 2011, 10, 67-70. [CrossRef]

102. Werner, D.H.; Kuhirun, W.; Werner, P.L. The Peano-Gosper fractal array. IEEE Trans. Antennas Propag. 2003, 51, 2063-2072. [CrossRef]

103. Zhu, J.; Hoorfar, A.; Engheta, N. Peano antennas. IEEE Antennas Wirel. Propag. Lett. 2004, 3, 71-74.

104. Da Silva, M.R.; Nobrega, C.D.; Silva, P.H.D.; D'Assuncao, A.G. Stable and compact multiband frequency selective surfaces with Peano pre-fractal configurations. IET Microw. Antennas Propag. 2013, 7, 543-551. [CrossRef]

105. Oraizi, H.; Hedayati, S. Miniaturization of Microstrip Antennas by the Novel Application of the Giuseppe Peano Fractal Geometries. IEEE Trans. Antennas Propag. 2012, 60, 3559-3567. [CrossRef]

106. Sharma, N.; Singh, G.P.; Sharma, V. Miniaturization of fractal antenna using novel Giuseppe Peano geometry for wireless applications. In Proceedings of the 2016 IEEE 1st International Conference on Power Electronics, Intelligent Control and Energy Systems (ICPEICES), Delhi, India, 4-6 July 2016; pp. 1-4.

107. Vegesna, N.; Yugandhar, K.; Bharathi, D.V.; KrishnaKanth, V. Giuseppe Peano Fractal Antenna for Application in X to KA Bands. J. Comput. Theor. Nanosci. 2019, 16, 1284-1288. [CrossRef]

108. Singh, G.P.; Sharma, N. Novel Design of Fractal Antenna using Giuseppe Peano Geometry for Wireless Applications. Int. J. Comput. Appl. 2016, 150, 975-8887.

109. Goyal, A.; Alphones, A.; Karim, M.F.; Ong, C.L. A compact monopole fractal antenna for TV white space energy harvesting applications. In Proceedings of the 2015 IEEE International Symposium on Antennas and Propagation \& USNC/URSI National Radio Science Meeting, Vancouver, BC, Canada, 19-24 July 2015; pp. 2437-2438.

(C) 2020 by the authors. Licensee MDPI, Basel, Switzerland. This article is an open access article distributed under the terms and conditions of the Creative Commons Attribution (CC BY) license (http://creativecommons.org/licenses/by/4.0/). 